\title{
An assessment of cloud top thermodynamic phase products obtained from A-Train passive and active sensors
}

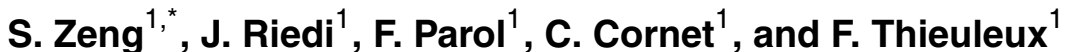

${ }^{1}$ Laboratoire d'Optique Atmosphérique, UMR8518, CNRS - Université de Lille 1, Sciences et Technologies, Lille, France

now at: NASA Langley Research Center, Hampton, Virginia, USA

Received: 2 September 2013 - Accepted: 4 September 2013

- Published: 12 September 2013

Correspondence to: J. Riedi (jerome.riedi@ univ-lille1.fr)

Published by Copernicus Publications on behalf of the European Geosciences Union.

Assessment of cloud phase products from

the A-TRain

S. Zeng et al.

\section{Title Page}

\section{Full Screen / Esc}

Printer-friendly Version

Interactive Discussion

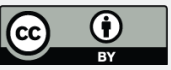




\section{Abstract}

The A-Train observations provide an unprecedented opportunity for the production of high quality dataset describing cloud properties. We illustrate in this study the use of one year of coincident POLDER (Polarization and Directionality of the Earth Re5 flectance), MODIS (MODerate Resolution Imaging Spectroradiometer) and CALIOP (Cloud-Aerosol Lidar with Orthogonal Polarization) observations to establish a reference dataset for the description of cloud top thermodynamic phase at global scale. We present the results of an extensive comparison between POLDER and MODIS cloud top phase products and discuss those in view of cloud vertical structure and optical properties derived simultaneously from collocated CALIOP active measurements. These results allow to identify and quantify potential biases present in the 3 considered dataset. Among those, we discuss the impacts of observation geometry, thin cirrus in multilayered and single layered cloud systems, supercooled liquid droplets, aerosols, fractional cloud cover and snow/ice or bright surfaces on global statistics of cloud phase derived from POLDER and MODIS passive measurements. Based on these analysis we define criteria for the selection of high confidence cloud phase retrievals which in turn can serve for the establishment of a reference cloud phase product. This high confidence joint product derived from POLDER/PARASOL and MODIS/Aqua can be used in the future as a benchmark for the evaluation of other cloud climatologies, for the assessment of cloud phase representation in models and the development of better cloud phase parametrization in the general circulation models (GCMs).

\section{Introduction}

Cloud thermodynamic phase is an important parameter for the studies of cloud microphysical and radiative properties and their effects on climate. The determination of cloud phase, in other words, the classification of cloud particles as being composed of liquid water, ice or a mixture of both, is a critical first step in the process of inferring
AMTD

6, 8371-8411, 2013

Assessment of cloud phase products from the A-TRain

S. Zeng et al.

\section{Title Page}

Abstract

Introduction

Conclusions

Tables

References

Figures

14

$>$ I

4

Back

Close

Full Screen / Esc

Printer-friendly Version

Interactive Discussion
$>$

\section{(1) Discussion}

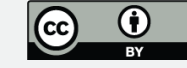


other cloud optical and microphysical properties (e.g. cloud optical thickness, particles size and water content) derived from satellite measurements. This is because the absorption and scattering behaviors for ice crystals greatly differ from those of water droplets. The inversion quality of cloud optical properties that depends on the ability to 5 match precomputed signal using radiative transfer code with actual measurements is of poor value if an erroneous phase assumption is made in the forward model calculation. Many efforts and progresses have been recently made to automatically discriminate and reasonably describe the cloud phase from the satellite measurements using various techniques (Pilewskie and Twomey, 1987; Baum et al., 2000; Goloub et al., 2000; 10 Hu et al., 2009). The distinctions between ice and liquid water clouds mainly lie in three aspects. First, liquid cloud droplets are usually warmer than ice crystals. It is hard for the supercooled droplets to remain in metastable state when the ambient temperature decreases down to $-40^{\circ} \mathrm{C}$ and also ice crystals are no longer existing above the melting temperature (Pruppacher and Klett, 1997). Secondly, the typical liquid droplets 15 are considered to have spherical shape and relatively small effective radii (ranging from 0.5 to $50 \mu \mathrm{m}$ and typically reff $<30 \mu \mathrm{m}$ ) (Hansen, 1971; Paltridge, 1974; Stephens et al., 1978) while non-spherical particles with relatively large effective radii (with extreme variable sizes: ranging from a few microns to $1000 \mu \mathrm{m}$ and typically reff $>30 \mu \mathrm{m}$ ) mainly characterize the ice crystals (Fu, 1996; Lawson et al., 1998). Thirdly, the refractive indexes that controls partly the scattering (real part) and absorption (imaginary part) properties of particles differ significantly between ice and liquid water at certain wavelengths. Therefore the distinct radiative behaviors, and especially their spectral variations, are helpful indicators for cloud phase identification and are widely used for remote sensing of cloud thermodynamic phase from satellites.

The combination of different methods to improve discrimination capabilities is increasingly used for cloud phase retrieval from satellite observations. For example, MODIS uses the spectral absorption differences between liquid droplets and ice crystals in short wave and near infrared bands (SWIR/VIS) (Pilewskie and Twomey, 1987) and also in two thermal infrared bands (Bi-spectral IR) (Baum et al., 2000; Strabala

\section{AMTD}

$6,8371-8411,2013$

Assessment of cloud phase products from the A-TRain

S. Zeng et al.

\section{Title Page}

Abstract Introduction

Conclusions

Tables

References

Figures

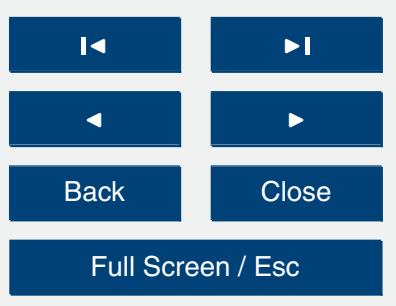

Printer-friendly Version

Interactive Discussion

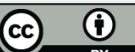


et al., 1994) to discriminate ice from liquid water phase (Platnick et al., 2003). POLDER uses the angular polarization at $865 \mathrm{~nm}$ (Goloub et al., 2000), and CALIOP uses the depolarization of backscattered light (Hu et al., 2009) for cloud phase retrievals. Both POLDER and CALIOP methods are taking advantage of the strong differences be5 tween spherical and non-spherical particles with respect to modification of polarization state during scattering events, particle shape being used as a very direct proxy for its phase. Moreover, the three sensors can use additional information about cloud top properties to help in cloud phase classification, for example, the cloud top temperature and pressure. Note that any single method mentioned hereabove, is not always able 10 to identify unambiguously the cloud phase for all cloud types and ambient conditions. For example, the conditions such as for cloud top temperature between 240 and $273 \mathrm{~K}$ where supercooled droplets or mixed phase can predominate, in multilayered or broken cloud systems, over snow/ice covered or temperature inversion regions, will make it difficult for some methods to determine cloud phase (Spangenberg et al., 2005; Wolters 15 et al., 2010; Kahn et al., 2011). It is thus highly desired to combine more distinct and independent methods in an algorithm that can help to gather more useful cloud phase information even in a complicate condition, benefiting their strengths and avoiding their weaknesses as illustrated by Riedi et al. (2010).

A logical and reasonable decision tree is so required in processing of the final cloud phase product from different combined methods. This requires a better understanding of both strengths and weaknesses of each retrieval method. The A-Train satellites give us an unprecedented opportunity for a joint study of these different cloud phase retrieval techniques. Past studies of cloud phase from sensors of the A-Train (e.g. POLDER, MODIS, CALIOP or AIRS) have mainly focused on individual case analy25 sis or radiative transfer simulation (Riedi et al., 2010; Chylek et al., 2006; Cho et al., 2009; Kahn et al., 2011) and had not concerned the global long-term assessment of cloud phase using both passive and active sensors in this A-Train constellation. The statistical assessment of cloud phase done in this paper allows to exhibit more representatively the potential issues and virtues in each algorithm compared to a particular

\section{AMTD}

$6,8371-8411,2013$

Assessment of cloud phase products from the A-TRain

S. Zeng et al.

\section{Title Page}

Abstract Introduction

Conclusions

Tables

References

Figures

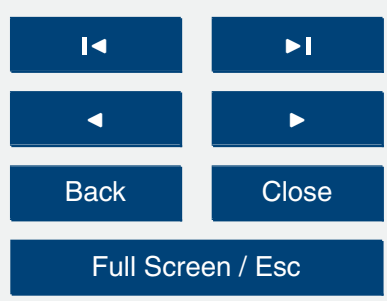

Printer-friendly Version

Interactive Discussion

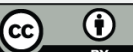


case study. Moreover, we hope to improve the phase inversion and create a much needed high confidence cloud thermodynamic phase dataset on which could rely future work on cloud phase parameterizations in cloud resolving and climate models.

A brief overview of the different cloud phase retrieval algorithms used for POLDER, 5 MODIS and CALIOP and a description of associated datasets is provided in the second section. A third section is devoted to the global comparison of cloud phase products between POLDER and MODIS. Further assessment of the two datasets obtained from the two passive sensors is done against CALIOP and results are provided in section four. The potential biases and analysis of additional information on cloud structure are 10 discussed in section five. A summary of main findings and outlook is provided in the last section.

\section{Dataset and algorithm descriptions}

Two datasets obtained from POLDER, MODIS and CALIOP and created by the ICARE data and services center are used for this study. The first one is a joint POLDER/MODIS

(PM) dataset containing all Aqua/MODIS collection 5 level 2 cloud products and PARASOL/POLDER3 collection 2 level 2 cloud products collocated and reprojected on a common integerized sinusoidal grid (Zeng et al., 2011). POLDER single orbit files are used as reference for the collocation of the coincident MODIS granules using a sinusoidal grid centered on POLDER ascending node longitude. This new dataset preserves completely POLDER cloud products while the MODIS products are averaged within each POLDER superpixel via a nearest pixel approximation collocation. The final joint products thus provide all coincident POLDER and MODIS cloud products at the same spatial resolution of about $20 \times 20 \mathrm{~km}^{2}$. Note that the official cloud phase products from MODIS use index values representation ( 1 for ice, 2 for liquid, 3 for mixed). In
PM dataset, this cloud product is reproduced by counting the number of ice, liquid and mixed pixels in the POLDER super-pixel. If all of MODIS pixels in the POLDER superpixel have ice (liquid or mixed) phase, the final phase is directly labeled as ice (liquid
AMTD

$6,8371-8411,2013$

Assessment of cloud phase products from the A-TRain

S. Zeng et al.

\section{Title Page}

Abstract Introduction

Conclusions

Tables

References

Figures

14

$\Delta$

4

Back

Close

\section{Full Screen / Esc}

Printer-friendly Version

Interactive Discussion

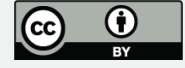


or mixed). In other situations where both liquid and ice are present within a POLDER superpixel, either liquid or ice dominated phase, or mixed phase is labeled depending on the number of liquid and ice pixels.

The second dataset called CALTRACK is a subset of products from POLDER, 5 MODIS and different other sensors or meteorological reanalysis extracted along the CALIOP curtain. The level 2 CALTRACK products contain coincident data issued from several sensors under the CALIOP tracks at $5 \mathrm{~km}$ horizontal resolution. These coincident products of different sensors are sampled and filtered using the official CALIOP products files as a reference space for collocation again using the nearest pixel approx10 imation. Note that the CALTRACK dataset sample is much smaller than the PM one because of the narrow CALIOP swath. The period considered for the following study ranges from December 2007 to November 2008.

\subsection{POLDER}

POLDER is multi-polarization, multi-directional (16 directions) and multi-spectral (443$151020 \mathrm{~nm}$ ) imaging radiometer with a native resolution of $6 \mathrm{~km} \times 7 \mathrm{~km}$ to provide global and repetitive observations of the solar radiation and polarized radiance reflected by the earth-atmosphere system (Deschamps et al., 1994). It uses the angular characteristics of polarized reflectance at $865 \mathrm{~nm}$ (where the molecular scattering contribution is weak) to discriminate cloud phase (Goloub et al., 2000). The method is based on 20 the strong dependence of polarized scattering behaviors on particle shape and size. Unlike the total radiance or the degree of linear polarization, the polarized reflectance does not depend on the cloud optical thickness $(\tau)$ as it saturates rapidly for $\tau$ greater than about 3 depending on the details of cloud microphysics (Goloub et al., 1994; Riedi et al., 2010). Looking from satellites at a cloudy system, the polarized light is primarily 25 formed in the upper cloud layer, mainly corresponds to single scattering and is less sensitive to multiple scattering effects. When observed from multiple directions, the observed angular features depend strongly on the polarized phase function of scatterers which in turn is determined by the shape, size distribution and refractive index

\section{AMTD}

$6,8371-8411,2013$

Assessment of cloud phase products from the A-TRain

S. Zeng et al.

Title Page

Abstract

Introduction

Conclusions

Tables

References

Figures

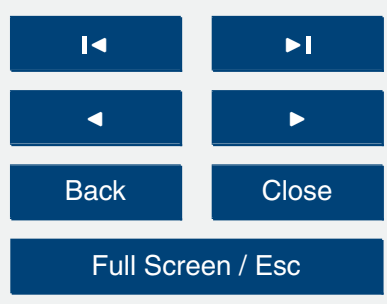

Printer-friendly Version

Interactive Discussion 
of the cloud particle. Simulations assuming that liquid clouds are typically composed of spherical particles and ice clouds are mostly composed of non-spherical particles show quite different polarized features for ice and liquid clouds (Goloub et al., 2000). For example, the polarization angular signature shows a remarkable peak (cloudbow) 5 for liquid clouds at around $140^{\circ}$ of scattering angles. For scattering angles less than about $90^{\circ}$, polarized reflectance signature tends to be positive with a negative slope for ice clouds whereas it increases with scattering angle for liquid clouds.

\subsection{MODIS}

MODIS is a relatively high spatial resolution $(1 \mathrm{~km})$ and wide spectral $(0.41-15 \mu \mathrm{m})$ 10 imaging radiometer that provides global observations of atmospheric properties (Platnick et al., 2003). Its phase retrieval algorithm takes advantages of combined information from the couple of a visible and a near infrared bands, the couple of two thermal infrared bands and cloud top brightness temperature at $11 \mu \mathrm{m}$. These retrieval methods are based on that the absorption for ice and liquid clouds at one band is approxi15 mately equal but diverges at another band. The final products from the combined methods used in this study are Cloud_Phase_Infrared (refereed as MODIS IR phase) and Cloud_Phase_Optical_Properties(refereed as MODIS phase). If not otherwise specified, cloud phase used for the comparison with POLDER is the latter one as it corresponds to the daytime algorithm and benefits from the combination of both solar and thermal 20 infrared measurements.

\subsubsection{Near and shortwave infrared information}

The physical principle of the SWIR/VIS ratio method is that liquid droplets and ice crystals exhibit different absorption properties in the solar band at $0.645 \mu \mathrm{m}$ and in the near infrared band at 2.13 or $1.64 \mu \mathrm{m}$ (Curran and Wu, 1982; King et al., 1997; 25 Pilewskie and Twomey, 1987). In the visible band, the imaginary part of refractive index that dominates the absorption ability can be neglected for both liquid and ice water, but
AMTD

$6,8371-8411,2013$

Assessment of cloud phase products from the A-TRain

S. Zeng et al.

\section{Title Page}

Abstract

Introduction

Conclusions

Tables

References

Figures

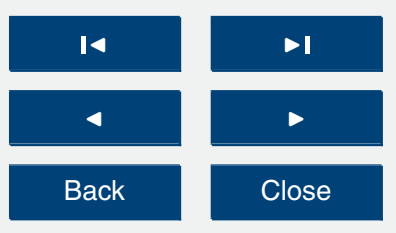

Full Screen / Esc

Printer-friendly Version

Interactive Discussion 
in near infrared bands, the imaginary part becomes non-negligible for both phases and is greater for ice than for liquid water for the two MODIS bands considered. The absorption appears thus more marked after radiation has traveled through an ice cloud if all other microphysical properties in clouds (e.g. particle size, shape and density) are 5 kept the same. With the experimental values (thresholds) of reflectance ratio $(2.13 \mu \mathrm{m}$ over $0.654 \mu \mathrm{m}$ or $1.64 \mu \mathrm{m}$ over $0.654 \mu \mathrm{m}$ reflectances), ice and water clouds can be separated, ice clouds usually exhibiting a significantly lower SWIR/VIS ratio compared to liquid clouds.

\subsubsection{Thermal infrared information}

10 The principle of the bi-spectral infrared method is also that it exists differences in the spectral absorption behavior for liquid droplets and ice crystals for the two thermal infrared (IR) bands at $8.5 \mu \mathrm{m}$ and $11 \mu \mathrm{m}$ (Baum et al., 2000; Menzel et al., 2006). The imaginary parts of refractive index at $8.5 \mu \mathrm{m}$ are approximately equal to each other for both liquid and ice but diverge significantly at around $11 \mu \mathrm{m}$ with ice having greater absorption. The IR bi-spectral method implemented in MODIS collection 5 products uses in addition the cloud top brightness temperature at $11 \mu \mathrm{m}$ to separate ice and liquid phases for clouds. Generally, the positive values of brightness temperature difference $\left(B T D_{8.5}-B T D_{11}\right)$ are associated with ice clouds and negative values suggest water clouds or clear sky.

\subsection{CALIOP}

CALIOP is an active two wavelength polarization-sensitive lidar with a footprint of $100 \mathrm{~m}$ to provide unique measurement to improve our understanding of global radiative effects of aerosols and clouds in the Earth's climate system (Winker et al., 2003). It primarily uses layer integrated depolarization of the backscattered light and cloud top temperature (derived from measured altitude and meteorological temperature profile) to classify cloud phase as ice or liquid water. The detection of mixed phase requires vertical pro-
AMTD

6, 8371-8411, 2013

Assessment of cloud phase products from the A-TRain

S. Zeng et al.

\section{Title Page}

Abstract Introduction

Conclusions

Tables

References

Figures

14

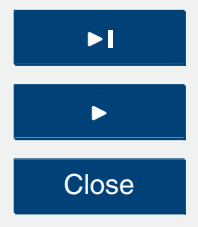

Back

Close

\section{Full Screen / Esc}

Printer-friendly Version

Interactive Discussion 
files of depolarization and is not included in collection the 2 operational algorithm. This method employed by CALIOP is based on the different characteristics of backscattering and polarized scattering behaviors existing between spherical and non-spherical particles. When clouds are optically thin and single scattering dominates, the backscattered 5 signal from spherical particles (e.g. liquid droplets and spherical aerosols) is not depolarized, making the perpendicularly polarized component of backscatter very close to zero. For randomly oriented non-spherical particles (e.g. ice clouds, non-spherical aerosols), the backscattering light is highly depolarized (Hu et al., 2009; Vaughan et al., 2004) which allows to discriminate between liquid and ice again using particles shape 10 as a proxy for their phase.

\subsection{Strengths and weaknesses of individual methods}

Different methods have different known strengths and weaknesses for cloud phase retrieval which we discuss in the following. Note that all techniques are inherently subject to ambiguities in case of multilayered cloud systems when thin cirrus overlaps the wa15 ter clouds, or when a cirrus is too thin to impact significantly the top of atmosphere radiation.

\subsubsection{The SWIR/VIS ratio method}

The strengths and weaknesses of SWIR ratio method have been summarized by Pilewskie and Twomey (1987), King et al. (2004), Chylek et al. (2006), and Riedi et al. (2010). In the following conditions, the phase information may be ambiguous. First, for the very thin clouds with optical thickness smaller than 1 , the optical path along which absorption can occur is too short to provide useful phase information. Secondly, for the clouds with large droplets or small ice crystals, the contrast of absorption between ice and liquid water is not large enough and make the phase separation difficult. A third class of ambiguous situations is over the surfaces where the albedo in near-infrared and visible bands are too different and significantly impact the SWIR/VIS ratio (e.g.

\section{AMTD}

$6,8371-8411,2013$

Assessment of cloud phase products from the A-TRain

S. Zeng et al.

\section{Title Page}

Abstract Introduction Conclusions

Tables

References

Figures

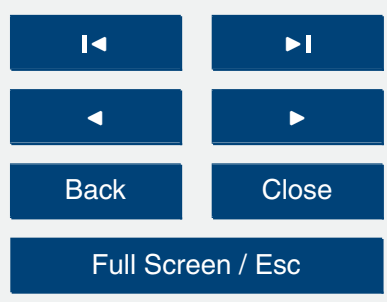

Printer-friendly Version

Interactive Discussion 
in sun-glint and over snow). Finally, the presence of mixed phase clouds makes the separation ambiguous as the absorption tends to an average value of the two parts.

\subsubsection{The Bi-spectral IR method}

The advantages and limitations of bi-spectral IR method have been summarized by

5 Spangenberg et al. (2005), Chylek et al. (2006), Menzel et al. (2006), Riedi et al. (2010), and Kahn et al. (2011). The accuracy of phase separation using this method will be first affected by the surface emission that can decrease at $8.5 \mu \mathrm{m}$ much more significantly than at $11 \mu \mathrm{m}$ over non-vegetated land. Secondly, the water vapor contained in the atmosphere tends to radiatively act as liquid clouds. Thirdly, and similarly 10 to the shortwave near infrared method, the technique is sensitive to the particle size with small particles tending to increase the BTD relative to large particles because of increased scattering. A fourth issue is linked with the presence of clouds with the cloud top temperatures between 238 and $273 \mathrm{~K}$ that may contain supercooled liquid droplets, ice crystals or a mixture of both. This often happens in the Storm Tracks of each hemi15 sphere and is a known issue of infrared based techniques (Kahn et al., 2011). Finally, the presence of temperature inversion, which occurs often in polar regions can also lead to ambiguous situations.

\subsubsection{Angular polarization method}

The strengths and weaknesses of POLDER cloud phase retrieval method have been summarized from the comparison work with the active sensor and ISCCP measurements (Chepfer et al., 1999; Riedi et al., 2000, 2001), and also from the studies of radiative transfer simulations (Goloub et al., 1997, 2000; Riedi et al., 2010). Considering the POLDER algorithm, the retrieval quality of the cloud phase strongly depends on the number and nature of tests effectively applied and therefore on the available samplings of the scattering angle. Retrieval confidence and therefore potential biases will vary with average observation geometries. Secondly, for unsaturated polarization
AMTD

6, 8371-8411, 2013

Assessment of cloud phase products from the A-TRain

S. Zeng et al.

\section{Title Page}

Abstract Introduction

Conclusions

Tables

References

Figures

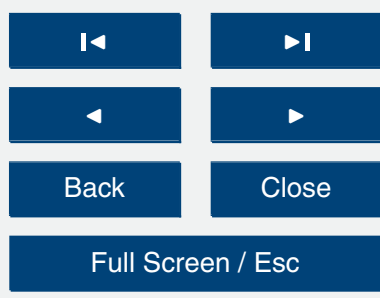

Printer-friendly Version

Interactive Discussion 
signal from cloud edges or thin clouds, polarization feature is not well defined, leading to potential misclassification. Similarly, the mixing of information from the neighboring pixels (aerosols/clear sky/clouds with different phases) or lower surfaces (especially for oblique directions) can impact the angular behaviors of polarized signatures and there5 fore the phase detection. For instance, low liquid highly broken clouds or cloud edges are often classified as ice. Cloud phase determination for thin cirrus overlaying the low liquid clouds depends on the upper cirrus optical thickness. For COT $>2$ to 3 , ice will be detected whereas similar situation will be flagged as liquid if cirrus COT $<1$. For $1<\mathrm{COT}<2$, the underlying liquid feature could pass though the cirrus and the mixed 10 or undetermined flag may be labeled. For single layered cirrus, the final decision is less biased because of the similar polarized feature from the ground.

As a summary and as already largely discussed by Riedi et al. (2010), no single method is perfect for detecting the cloud phase in all situations. The statistical assessment of cloud phase derived from different methods is therefore necessary and 15 important. Results of the intercomparison between POLDER and MODIS are provided in the next section.

\section{Global distribution observed from POLDER and MODIS}

The first part of the analysis is dedicated to a statistical and global comparison of cloud phase observed from POLDER and MODIS. From the PM dataset, each pixel observed

\section{AMTD}

$6,8371-8411,2013$

Assessment of cloud phase products from the A-TRain

S. Zeng et al.

\section{Title Page}

Abstract

Introduction

Conclusions

Tables

References

Figures

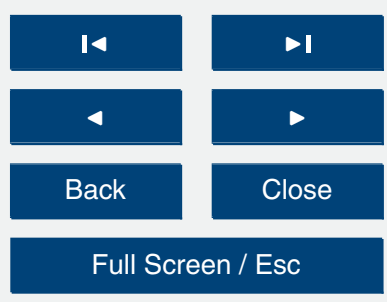

Printer-friendly Version

Interactive Discussion 


\subsection{Global statistics}

First, we focused on the 9 combinations of phase (hereafter referred to as classes) and quantify the global agreement and disagreement in phase detection according to different environmental conditions and geographic locations. In Figure 1, we plotted 5 the annual global percentages of the 9 classes for different environments in order to see in which conditions POLDER and MODIS tend to present consistent or inconsistent phase determination. From the figure, we find that over all cloudy scenes, the total frequency of agreement on phase between POLDER and MODIS reaches about $73 \%$ of all pixels with $50 \%$ of liquid clouds, $23 \%$ of ice clouds and about $27 \%$ of the

pixels showing disagreement (subfigure a). Concerning the overcast scenes that are referred as overcast by both POLDER and MODIS, the agreement on phase raises to $76 \%$ (subfigure c), but for the broken scenes that are determined as broken by both sensors, the overall agreement on phase decreases to $69 \%$ (subfigure b). It shows an even better agreement in case of overcast single layered clouds selected using MODIS multilayer flag (Wind et al., 2010), for which up to $93 \%$ of pixels show consistent phase decisions between MODIS and POLDER (subfigure d). Not surprisingly, however the agreement on phase gets worse in case of overcast multilayered cloud systems with only $67 \%$ of pixels in agreement (subfigure e) and even worse with only $65 \%$ of pixels over snow covered surface where both clouds detection and phase detection may be at issue for the two sensors (subfigure f).

Surprisingly, only very few situations are detected as mixed by both sensors whereas a large fraction of the disagreement comes from completely opposite decisions, where MODIS detects an ice cloud (respectively liquid) and POLDER a liquid (respectively ice) cloud (11.7 and $4.5 \%$ respectively). The POLDER-mixed \& MODIS-liquid class represents about $5.6 \%$ of all cases.

Comparing subfigures $\mathrm{b}$ and $\mathrm{c}$, we see that the confident liquid (ice) clouds are relatively speaking more (less) frequent for broken scenes than overcast scenes, which is logical because broken clouds correspond frequently to small clouds such as cumulus
AMTD

$6,8371-8411,2013$

Assessment of cloud phase products from the A-TRain

S. Zeng et al.

\section{Title Page}

Abstract Introduction

Conclusions

Tables

References

Figures

14

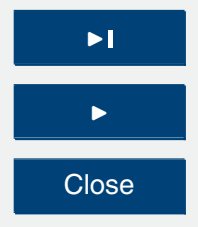

Back

Close

\section{Full Screen / Esc}

Printer-friendly Version

Interactive Discussion 
clouds mostly in liquid phase. We also observe a greater percentage for POLDER-ice (color: orange) or mixed (color: brown) \& MODIS-liquid clouds (orange: $8.9 \%$ or brown: $9.9 \%$ ) in broken scenes than in overcast scenes (orange: $0.8 \%$ or brown: $1.5 \%$ ). In fact, scenes presenting mixture of clouds and clear sky (or aerosols) are expected to 5 cor complicate POLDER phase detection as we will see in Sects. 5.4 and 5.5.

Considering the multilayered (subfigure e) and single layered (subfigure d) overcast cloud scenes, we can see that the POLDER-liquid \& MODIS-ice (red, equal to $24 \%$ ) clouds and POLDER-mixed \& MODIS-ice (pink, 6\%) clouds represent a significant part of the multilayered cloud systems while these classes are barely observed for 10 the single layered cloud systems. This tends to indicate that, in case of multilayered cloud systems, MODIS is sensitive to the upper layer cloud phase while POLDER is still impacted by the lower layer. Obviously for the multiple structures of clouds, the radiation through the upper thin layer clouds can complicate the phase detection (see Sect. 5.2).

15 Over snow/ice (subfigure f), POLDER-liquid \& MODIS-ice class and POLDER-liquid \& MODIS-mixed class take an important parts of percentage for about 18 and $7 \%$ of all cases (see Sect. 5.6).

\subsection{Geographical distribution}

From the above, we see that cloud phase detection shows satisfactory agreement al20 though using different methods, but also it illustrates the different sensitivity in detecting phase depending on types of cloudy scenes. Here, we look into the geographical distributions of the 9 classes of combined phase over the globe (Fig. 2) to determine the locations of confident and ambiguous phase classes. This helps associating the confident and ambiguous situations with different environmental conditions. In Fig. 2, 25 the colormap presents the annual frequencies of each class of combined phase (the sum of the occurrence frequencies for the 9 combined phases is equal to $100 \%$ ). We see that the confident ice clouds (consistent ice phase between POLDER \& MODIS) are mostly located in the Storm Tracks and in the ITCZ, where are known to occur
AMTD

$6,8371-8411,2013$

Assessment of cloud phase products from the A-TRain

S. Zeng et al.

Title Page

Abstract

Introduction

Conclusions

Tables

References

Figures

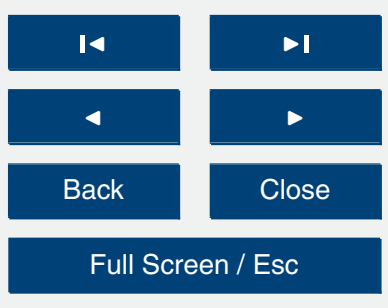

Printer-friendly Version

Interactive Discussion 
large amount of thick high clouds associated with deep convection (Fig. 2 (1-1)). The confident liquid clouds (consistent liquid phase between POLDER \& MODIS) can be found mostly in subtropical subsidence regions where clouds often occur as broken and over ocean to the western coast of the continents where low stratocumulus are 5 largely predominant (Fig. 2 (2-2)). The confident mixed clouds are significant in Storm Tracks and in Polar regions (Fig. 2 (3-3)). The clouds labeled as ice by POLDER but liquid by MODIS (Fig. $2(2-1)$ ) occur around Africa and China where there are often heavy aerosol loadings over low water clouds (see Sect. 5.4). The clouds labeled as liquid by POLDER and ice by MODIS (Fig. 2 (1-2)) are vast in the ITCZ where often ap10 pear multilayered clouds and a great number of supercooled droplets associated with strong convection in clouds (see Sects. 5.2 and 5.3). These also occur frequently over snow covered surface and deserts where both the surface emission and atmosphere profile are extremely peculiar (see Sect. 5.6). The clouds labeled as mixed by MODIS regardless of POLDER decision, often occur over snow (Fig. 2 (3-1), (3-2) and (3-3)).

15 The clouds labeled as mixed by POLDER and liquid by MODIS (Fig. 2 (2-3)) appear more frequently in the regions where broken clouds are predominant (see Sect. 5.5) or where clouds can be overlaid by aerosols such as around Africa (see Sect. 5.4). The clouds labeled as mixed by POLDER and ice by MODIS (Fig. 2 (1-3)) occur in the Storm Tracks and the ITCZ, similar to the situation in Fig. 2 (1-2), which is also associated to the multilayered clouds and supercooled droplets in the strong convective clouds (see Sects. 5.2 and 5.3).

The above geographical distributions of the 9 classes observed from POLDER and MODIS can be explained largely by known properties of the global cloud cover (high, low, multilayered) and other environmental conditions (aerosols, snow covered sur25 faces) and are consistent with the strengths and weaknesses of techniques described previously. These results represent however the first global quantification of confident and ambiguous cloud phase decisions from POLDER and MODIS. To take a step further, we analyze in the following section the details of the cloud structure and environmental conditions associated to the different classes. In particular, thanks to the
AMTD

6, 8371-8411, 2013

Assessment of cloud phase products from the A-TRain

S. Zeng et al.

\section{Title Page}

Abstract

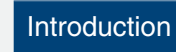

Conclusions

Tables

References

Figures

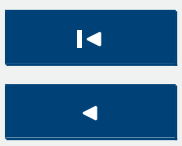

$>$ I

Back

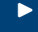

Close

Full Screen / Esc

Printer-friendly Version

Interactive Discussion 
CALIOP observations, more insight can be quantitatively obtained regarding the impact of cloud vertical structure.

\section{Assessment of POLDER and MODIS products with CALIOP}

It appears clearly from the above studies that the 9 combined phase classes are not 5 randomly distributed and are most likely associated with particular environmental conditions which need to be further studied and discussed. In the next step, the cloud phase from the active sensor CALIOP will be used to help understanding each combined phase detected by passive sensors. Furthermore, it will help evaluating how confident is the phase information retrieved for each and the combination of both sensors and help evaluating the potential biases for each method.

\subsection{Analysis of coincident lidar backscatter and depolarization signal}

CALIOP can identify cloud phase mainly owning to the different features of layerintegrated depolarization $(\delta)$ and layer-integrated attenuated backscatter at 532nm $(\gamma)$ between ice and liquid clouds. When observed in a $\gamma-\delta$ diagram, clusters of liquid and ice clouds are easily discriminated (Hu et al., 2009). Although they overlap partly in some regions of that space, this type of diagram appears extremely useful for identifying the nature of an ensemble of pixels as will be illustrated in the following.

In this part, we also used CALIOP to discriminate opaque clouds (no signals returned from the ground) and plotted the clusters of pixels corresponding to each of the 9 classes in a $\gamma-\delta$ diagram. Results are plotted in Fig. 3 (for all cloudy scenes) and Fig. 4 (for overcast opaque cloudy scenes). We will discuss separately the cases of agreement and disagreement between active and passive sensors.

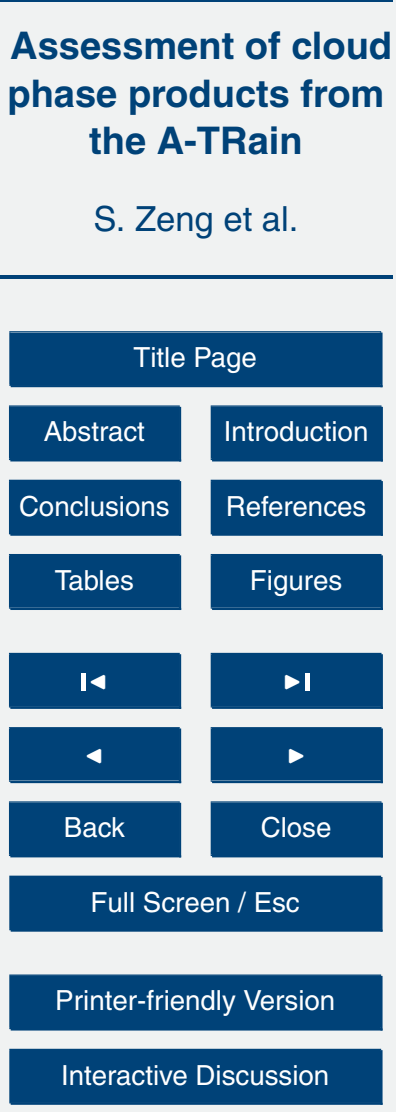




\subsubsection{Confident classes with POLDER and MODIS in agreement (subplots on the diagonal)}

The confident ice clouds (Figs. $3(1-1)$ and $4(1-1)$ ) have typical $\gamma-\delta$ feature of ice clouds with low backscattered radiation and high depolarization as shown by Hu et al. (2009).

5 The confident liquid clouds (Figs. 3 (2-2) and 4 (2-2)) similarly exhibit typical $\gamma$ - $\delta$ feature of liquid clouds with relative high backscattered radiation and that the depolarization increases with backscattered light. The cluster corresponding to confident mixed clouds (Figs. 3 (3-3) and 4 (3-3)) is located right in the overlapping region of liquid and ice clouds. In conclusion, for confident phase classes, the $\gamma-\delta$ features from CALIOP agree extremely well with the phases derived from passive sensors and confirms the accuracy of detected phase when both passive sensors are in agreement.

\subsubsection{Ambiguous classes with decisions in disagreement or low confidence}

For POLDER-liquid \& MODIS-ice (Figs. 3 (1-2) and 4 (1-2)), POLDER-ice \& MODISliquid (Figs. 3 (2-1) and 4 (2-1)), POLDER-ice \& MODIS-mixed (Figs. 3 (3-1) and 4 (315 1)) and POLDER-liquid \& MODIS-mixed (Figs. 3 (3-2) and 4 (3-2)) clouds, the clusters observed in the $\gamma-\delta$ space tend to indicate that CALIOP confirms POLDER phase identification in a large majority of the cases. For POLDER-mixed \& MODIS-ice (Figs. 3 (13 ) and 4 (1-3)) and POLDER-mixed \& MODIS-liquid (Figs. 3 (2-3) and 4 (2-3)) clouds, CALIOP in majority agrees with MODIS most of the time. This would suggest when

one instrument identifies either liquid or ice, but the other identifies a mixed situation, CALIOP tends to confirm the decision made for either ice or liquid and not mixed. The most important changes between overcast and all scenes appear on the POLDER-ice \& MODIS-liquid clouds (Figs. 3 (2-1) and 4 (2-1)). In this particular case, we clearly see that some pixels labeled as ice clouds by POLDER and liquid clouds by both MODIS and CALIOP, come partially from broken cloud scenes, corresponding to either broken liquid water clouds or thin aerosol layer above broken liquid water clouds (Waquet et al., 2009). Another, although less significant difference, appears for the POLDER-

AMTD

$6,8371-8411,2013$

Assessment of cloud phase products from the A-TRain

S. Zeng et al.

\section{Title Page}

Abstract Introduction

Conclusions

Tables

References

Figures

14

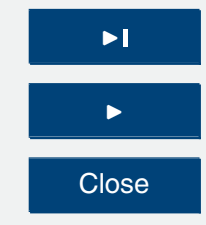

Back

Close

\section{Full Screen / Esc}

Printer-friendly Version

Interactive Discussion 
mixed \& MODIS-liquid clouds for which the cluster seems more ambiguous for overcast situations as it shifts toward ice in the $\gamma-\delta$ space.

In summary, CALIOP $\gamma-\delta$ features are very consistent with MODIS and POLDER phase products when those two agree. In cases where POLDER and MODIS have

5 inconsistent decisions, CALIOP tends to agree with POLDER more often. This is most probably because both POLDER and CALIOP use somehow similar proxy for phase retrieval as both are based on the polarization analysis and are in fact particle shape determination methods. The statistics provided here represent a first quantitative assessment of POLDER and MODIS phase products for various cloud cover scenario 10 and demonstrate the high quality of the joint dataset calling for a synergistic use of both products when trying to build global statistics of cloud thermodynamic phase.

\subsection{Comparison against CALIOP cloud phase product}

Analysis of the data clusters in the $\gamma-\delta$ space obtained from CALIOP provides a global qualitative understanding of each of the 9 classes obtained when merging POLDER and MODIS products. However, phase detection from CALIOP also needs to rely on given thresholds to separate liquid from ice and users might be interested in knowing quantitatively how much agreement can be obtained between the POLDER, MODIS and CALIOP phase products. Therefore we also analyze the CALIOP phase decisions for the 9 combined classes so as to quantify the agreement between the active and pas20 sive sensors. In Fig. 5 (for all opaque clouds), Fig. 6 (for overcast opaque clouds) and Fig. 7 (for broken opaque clouds), we computed the fraction of ice and liquid phases determined by CALIOP for each class obtained from combination of POLDER and MODIS (one-year statistics over the globe) according to different cloudy scenes. In good consistency with CALIOP observations of the $\gamma-\delta$ features, CALIOP cloud phase product shows similar tendencies when compared to POLDER and MODIS products.

For all opaque clouds (Fig. 5) in confident cloud phase classes, i.e. when POLDER and MODIS agree, (the pie charts on the diagonal), more than $99 \%$ of pixels are labeled as ice by CALIOP when the two passive sensors identified ice phase (Fig. 5 (1-1)) and

\section{AMTD}

6, 8371-8411, 2013

Assessment of cloud phase products from the A-TRain

S. Zeng et al.

\section{Title Page}

Abstract Introduction

Conclusions

Tables

References

Figures

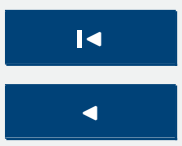

$\Delta$

Back

Close

\section{Full Screen / Esc}

Printer-friendly Version

Interactive Discussion
$>$

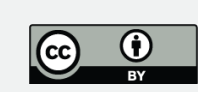


about $95 \%$ of pixels are labeled as liquid by CALIOP when the two passive sensors agreed on liquid phase. In conclusion, the agreement between CALIOP and the passive sensors is extremely good when the two passive sensors agree on the phase decision.

For all opaque clouds (Fig. 5) in inconsistent cloud phase classes, again in good

5 agreement with previous observations of the $\gamma$ - $\delta$ features from CALIOP, CALIOP phase decision tends to agree preferentially with either POLDER or MODIS depending on particular situations. For POLDER-ice \& MODIS-liquid clouds (Fig. 5 (2-1)), CALIOP show better agreement with POLDER (64\%). For POLDER-liquid \& MODIS-ice clouds (Fig. 5 (1-2)), CALIOP again confirms POLDER decision in a large majority (80\%). For 10 clouds detected as mixed from any one sensor, CALIOP phases show more agreements with the other sensor who identified either liquid or ice (the detailed percentages are shown in the charts).

Comparing the overcast cases in Fig. 6 and the broken cases in Fig. 7, the agreements between passive and active sensors present noticeable differences.

For confident ice clouds, $99 \%$ of agreement with CALIOP phase is obtained in overcast scenes and only $93 \%$ in broken scenes. For confident liquid clouds, about $96 \%$ of agreement is reached for overcast scenes whereas only $79 \%$ of agreement is found for broken scenes. In conclusion, and not surprisingly, the agreement between passive and active sensors decreases for broken scenes even though the scores of correct identification remain fairly high. For POLDER-mixed \& MODIS-ice clouds (Fig. 6 (1-3)) , fewer agreements between MODIS and CALIOP are found in broken scenes compared to overcast scenes. For and POLDER-mixed \& MODIS-liquid clouds (Fig. 6 (2-3)), POLDER-liquid \& MODIS-ice clouds (Fig. 6 (1-2)), POLDER-ice \& MODIS-mixed clouds (Fig. 6 (3-1)), POLDER-liquid \& MODIS-mixed clouds (Fig. 6 (32)) and POLDER-ice \& MODIS-liquid clouds (Fig. 6 (2-1)), more agreements to MODIS from CALIOP are found in broken scenes compared to overcast scenes. In conclusion, CALIOP in most of time shows better agreements with MODIS in cases of broken cloud with inconsistent phases between the two passive sensors. This is most probably related to the weaknesses of the POLDER algorithm in case of scenes mixing clear

\section{AMTD}

$6,8371-8411,2013$

Assessment of cloud phase products from the A-TRain

S. Zeng et al.

\section{Title Page}

Abstract Introduction

Conclusions

Tables

References

Figures

14

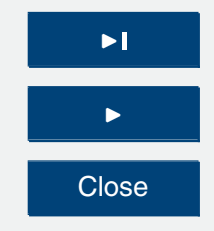

Back

Close 
and cloudy sky, a critical problem that is especially given by the rather coarse native resolution of the POLDER instrument.

\section{Discussion}

From the above analysis, we have seen that the passive and active sensors are in excellent agreement when both passive sensors agree with each other. However situations where the passive sensors disagree are more complex to understand but there is a high interest in understanding these differences as it can provide ground basis for building a meaningful joint dataset even in case of opposed decision between POLDER and MODIS. The strengths and weaknesses of each retrieval algorithm are not direct and depend on many factors. In this section, we go further to discuss some of problems in phase detection for these sensors and support the analysis with the help of CALIOP to better describe the vertical structure of the observed cloud cover.

\subsection{Observation geometry}

One of the challenging issues when building a global dataset from satellite sensors is retrieved cloud phase corresponding to certain geometry may be impacted by the 3-D effects and/or incorrect assumption about cloud microphysics used for the retrievals. Also, algorithms which depend on the observation of cloud under specific geometries are inherently subject to potential angular biases. This is the case for the POLDER algorithm for which the nature and number of applicable tests vary with accessible geometries. Also related, the observation of oriented plates by CALIOP motivated the change in viewing configuration of the lidar to prevent biases caused by specular reflection on oriented ice crystals (Hu et al., 2009). Also because the comparison to CALIOP observations are made for relatively constant observing geometries from the passive
AMTD

$6,8371-8411,2013$

Assessment of cloud phase products from the A-TRain

S. Zeng et al.

\section{Title Page}

Abstract

Introduction

Conclusions

Tables

References

Figures

14

$>1$

4

Back

Close

\section{Full Screen / Esc}

Printer-friendly Version

Interactive Discussion 
occurrence of potential angular biases in the cloud phase products. If strong angular biases were to exist, the validation results obtained along the CALIOP track might not be directly transferable to the full swath of the two passive sensors.

Figure 8 illustrates the angular dependency of the occurrence frequencies for the 53 phase products derived from MODIS and POLDER for all cloudy scenes. Note here, as MODIS is a crosstrack scanning radiometer, its viewing angles represent roughly the distances to the swath center, the pixels at nadir being located at the center of the swaths and oblique directions corresponding to the edges of the swaths. By convention, we use negative viewing angles when the associated relative azimuth is smaller 10 than $90^{\circ}$, in which case the sensor and the sun are on the same side with respect to satellite ground track. This corresponds roughly to backward scattering direction or to the eastern side of the swath. The MODIS view angle is taken as a reference as POLDER collocated products are intrinsically associated with different angles during the retrieval. This nevertheless provides a meaningful separation between the eastern 15 and western parts of the POLDER swath which are most likely to exhibit the largest angular related systematic differences.

This figure intending to identify the potential angular biases of cloud phase retrieval for each algorithm provides several interesting information. First, it can be seen that the MODIS IR phase detects the largest fraction of liquid phase. This phase shows fairly smooth variations against the viewing angles and symmetric distributions for both backward and forward scattering directions. Note that a "perfect" algorithm should not exhibit any view angle dependency on this type of plot as on global average liquid and ice clouds are expected to be uniformly distributed against view angle. Here we can see that liquid (respectively ice) cloud fractions determined from the IR phase algorithm have a slight increase (respectively decrease) with viewing angle. This slight increase of liquid clouds may be due to the longer absorption/emission path of water vapor above clouds in the more oblique directions. We also notice that the two other products (MODIS optical properties and POLDER) exhibit stronger and asymmetric variations against the viewing angle: POLDER detects more liquid fraction in
AMTD

6, 8371-8411, 2013

Assessment of cloud phase products from the A-TRain

S. Zeng et al.

\section{Title Page}

Abstract Introduction

Conclusions

Tables

References

Figures

14

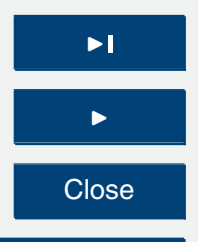

Full Screen / Esc

Printer-friendly Version

Interactive Discussion 
the western of the swath around $10^{\circ}-20^{\circ}$ of MODIS viewing angle (more pixels corresponding to cloudbow directions for POLDER). MODIS detects more ice fraction for the whole forward directions. As no obvious angular asymmetric characteristics of the cloud cover have been observed for either MODIS or POLDER (Zeng et al., 2011), 5 these asymmetric behaviors of cloud phase are most likely due to angular dependent retrieval biases produced by POLDER and MODIS phase algorithm. Both sensors employ visible channels to retrieve cloud phase. The total and polarized radiation reflected in these channels present angular distribution difference for the water and ice particles due to different phase function. For MODIS using the ratio of reflected radiation in near 10 infrared and VIS to separate cloud phase $\left(R_{\mathrm{SWIR}} / R_{\mathrm{VIS}}<\right.$ threshold is ice), a constant threshold against viewing angle is not sufficient to classify the phase with the same sensitivity. This is because the cloud particle phase functions show strong scattering peak in the forward directions, although the peak is in a narrow angular width, the multiple interactions could broaden the solid angle through which radiation is primar15 ily scattered and lead to a radiation maximum in a large range of forward directions (Bréon, 1992). Because solar radiation in forward directions increases, it is easier to get smaller ratio in forward directions than backward directions, and thus classify more ice clouds and less liquid clouds in these directions. POLDER uses angular variations of polarization. The strong polarization feature of liquid clouds in cloudbow directions can be more easily captured and identified, even with a thin layer of cirrus overlapping. This cloudbow test is also the most efficient test in phase detection algorithm. Since the probability to observe the cloudbow directions (scattering angles around $140^{\circ}$ ) in the western part of the swath around $10^{\circ}-30^{\circ}$ of MODIS viewing angle is twice the probability in other parts of the swath (not shown here), POLDER tends to detect more

\subsection{Multilayer clouds}

In Sect. 4, we have illustrated and discussed the comparisons of cloud phase between passive and active sensors for opaque clouds only. However, if a cloud such as a semi-

\section{AMTD}

$6,8371-8411,2013$

Assessment of cloud phase products from the A-TRain

S. Zeng et al.

\section{Title Page}

Abstract

Introduction

Conclusions

Tables

References

Figures

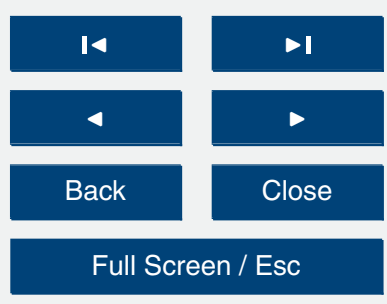

Printer-friendly Version

Interactive Discussion 
transparent thin cirrus if observed from the passive sensors POLDER and MODIS, the radiation from underlying surface may pass through the thin cirrus and bias the retrieved cloud phase toward the lower layer state. In these situations, the active sensor CALIOP, allows to detect the very thin cirrus which can help quantifying the impact of 5 thin cirrus on cloud phase detection from the passive sensors. Of specific importance and interest is the limit below which a thin cirrus overlaying a liquid cloud can not be detected by the passive sensors.

For cirrus overlying water clouds, the underlying surface that impacts the cirrus radiation to be measured is the water clouds, which have strong polarization signature 10 and can be much colder than the clear ground. For single layered cirrus, the underlying surface that impacts the cirrus is the clear ground, which has weak polarization and is usually warmer. The temperature of underlying surface could impact the phase derived from MODIS and the polarization of underlying surface could impact the phase derived from POLDER. So, the thin cirrus in multilayered or single layered cloud systems 15 need to be investigated separately. In Fig. 9, we selected the cirrus cases of interest from CALIOP observations and illustrated the ice detection frequency against the cirrus optical thickness (OT) of the upper most layer derived from CALIOP $532 \mu \mathrm{m}$ band for different types of cirrus system. The upper two subplots represent the ice fractions from one sensor and the lower two illustrate the fractions of the 9 combined phase classes as a function of the overlaying cirrus OT. Note that, since the cirrus OT can be confidently retrieved by CALIOP only if the retrievals are constrained (Young et al., 2008), we only investigated the impact from those thin cirrus having OT less than 1.4. From these plots, we can immediately notice that the ice detection probability derived from both POLDER and MODIS increases with cirrus OT for both cirrus in multilayered 25 (Fig. 9a) and single layered (Fig. 9b) systems. In other words, and not surprisingly, the thicker is the cirrus, the more probable that it will be identified as ice cloud. The probability to correctly identify the cirrus phase however depends strongly on both the cloud system type and the sensor considered. For cirrus over liquid clouds, when cirrus OT reaches 1 , about $90 \%$ of the cases are (correctly) identified as ice by MODIS
AMTD

$6,8371-8411,2013$

Assessment of cloud phase products from the A-TRain

S. Zeng et al.

\section{Title Page}

Abstract Introduction

Conclusions

Tables

References

Figures

14

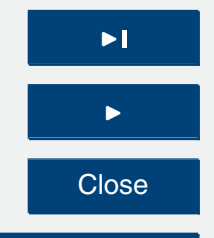

Full Screen / Esc

Printer-friendly Version

Interactive Discussion 
while at a cirrus OT of 1.4 , only about $60 \%$ of the cases can be correctly identified as ice by POLDER. This is consistent with previous theoretical analysis (Goloub et al., 2000; Riedi et al., 2010) showing that, if cirrus OT is less than 2, POLDER can still see the polarization signature of the underlying water clouds, because the strong po5 larization signal of the cloudbow can still be detected through the thin cirrus. MODIS has a higher sensitivity to thin cirrus over water clouds and accordingly, the probability to detect ice phase in these particular cases increases with the cirrus OT more rapidly than POLDER. For single layered cirrus, when the cirrus OT is equal to $0.3,80 \%$ of cirrus can be correctly identified as ice by POLDER while the cirrus OT equal to 0.3 , 10 only $40 \%$ of cirrus can be correctly identified as ice by MODIS and $80 \%$ of cirrus can be correctly identified as ice when cirrus OT reaches the value of 0.6. POLDER is more likely to detect ice phase in case of thin cirrus in single layered systems, which again agrees well with the theoretical study from Riedi et al. (2010).

For the fractions of 9 combined phase classes against the cirrus OT in Fig. 9, c 15 and $d$, the confident ice fraction increases with cirrus OT and confident liquid fraction decrease with cirrus OT. When the cirrus OT is greater than 1, the confident liquid cloud fraction decreases to about $10 \%(<5 \%)$ and confident ice cloud fraction increases to about $60 \%$ (> $80 \%$ ) in multilayered (single layered) cloud systems. The inconsistent phase classes occur significantly when the cirrus is thin. In multilayered cloud systems, the fraction of MODIS-ice and POLDER-liquid clouds reaches to a maximum of $40 \%$ when cirrus OT is about 0.6. The fraction of MODIS-ice and POLDER-mixed clouds reaches $10 \%$ when cirrus OT is between 0.6 and 1.4 . In single layered cloud systems, the fraction of MODIS-mixed and POLDER-ice clouds reaches to a maximum of $10 \%$ when cirrus OT is about 0.2. The fraction of MODIS-liquid and POLDER-ice clouds reaches to a maximum of $30 \%$ when cirrus OT is about 0.3 . This confirms that the sensitivity to thin cirrus is different between POLDER and MODIS. This first quantitative evaluation of their respective sensitivity in case of multilayered clouds provides useful information again for using the two datasets in a synergistic way.
AMTD

$6,8371-8411,2013$

Assessment of cloud phase products from the A-TRain

S. Zeng et al.

\section{Title Page}

Abstract Introduction

Conclusions

Tables

References

Figures

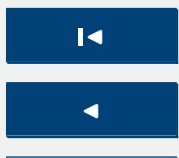

Back

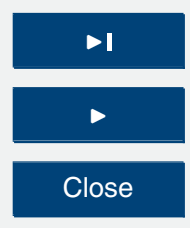

Full Screen / Esc

Printer-friendly Version

Interactive Discussion 


\subsection{Supercooled droplets}

As mentioned in Sect. 2, one major problem in phase detection for MODIS is related to frequent occurrence of liquid droplets at supercooled temperatures. Using IR brightness temperature or brightness temperature differences provides little information to 5 discriminate cloud phase due to the small contrast between supercooled and ice water. POLDER thanks to its polarization-based technique is not impacted by supercooled droplets because the polarization and the retrieved phase decision depends only on the particle shape. To assess the impact of supercooled droplets, we plotted in Fig. 10 the liquid fraction as a function of cloud top temperature determined by CALIOP. The data sample corresponds to one year of observations when CALIOP detects only water clouds. From this figure we see that, when cloud top temperature ranges between $0^{\circ}$ and $-40^{\circ}$, the liquid cloud fraction observed by MODIS is much lower than $100 \%$ and increases with cloud top temperature. This result indicates that from MODIS, supercooled droplets can be largely erroneously labeled as ice especially for higher level

15 (colder) supercooled droplets. However for POLDER, the liquid cloud fraction remains very close to $100 \%$ down to cloud top temperature below $-30^{\circ}$, especially for overcast clouds. In other words, POLDER can correctly identify those supercooled droplets that are unambiguously detected by CALIOP. This results clearly demonstrates once again the strong advantage of POLDER for establishing cloud phase statistics which are unbiased with respect to cloud temperature.

\subsection{Aerosols}

POLDER uses the polarized radiance to discriminate cloud phase. This information and therefore the correctness of retrieved phase can be greatly affected by the presence of aerosols, which have small sizes and can produce strong polarization signal observed as non-spherical shape and their polarization features are therefore close to those produced by ice particles in clouds. Since aerosols are much smaller than ice

\section{AMTD}

$6,8371-8411,2013$

Assessment of cloud phase products from the A-TRain

S. Zeng et al.

\section{Title Page}

Abstract

Introduction

Conclusions

Tables

References

Figures

14

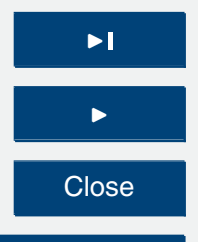

Full Screen / Esc

Printer-friendly Version

Interactive Discussion 
particles, small optical thicknesses (e.g. 0.225 ) are required to shut out the signal from the underlying water clouds especially beyond the cloudbow directions between $80^{\circ}$ to $120^{\circ}$ of scattering angle (Waquet et al., 2009). So according to the available scattering angle in the retrieval, the ice or mixed phase could be obtained from POLDER when 5 aerosols are present over the low water clouds. For MODIS, some large absorbing aerosols may act as ice crystals, however their contribution to total radiance is relatively much smaller than for polarization and can be neglected. As a consequence, we have already noticed in Sect. 4, the regions for POLDER-ice \& MODIS-liquid clouds (Fig. 2 (2-1)) and POLDER-mixed \& MODIS-liquid clouds (Fig. 2 (2-3)) are mostly 10 around Africa, and coincide with regions of frequent occurrence of heavy aerosols and aerosols events over low water clouds. This could be explained at least partly if we consider the aerosols over water clouds which tend to toggle ice detection by POLDER. As a summary, those aerosols with non-spherical shapes may cause issues in detecting the phase of low clouds when relying solely on the polarization measurement from 15 POLDER. Their influence on MODIS phase detection is small however. A combination of POLDER and MODIS again can provide meaningful information in these complex situations as was illustrated by Waquet et al. (2009) who used this differential sensitivity to reveal the presence of aerosols over low water clouds.

\subsection{Broken clouds}

20 When the polarization signal is unsaturated as often occurs for the broken clouds, POLDER may yield ambiguous phase decision (see Sect. 2). This is indeed what we observed in Figs. 3 and 4. Broken clouds can be detected as ice for POLDER and as liquid for both CALIOP and MODIS. Again in Fig. 10, we note that the liquid fraction of POLDER for level of cloud top temperature above $0^{\circ}$ is less than 1 especially for broken 25 clouds. About $20 \%$ of liquid broken clouds are incorrectly identified as ice by POLDER. This is due to the fact that clear sky polarization signature is similar to ice clouds and thus detected as such by POLDER. Concerning MODIS, there is no such problem because broken (low and liquid) clouds scene are a mixture of liquid clouds and clear sky.

\section{AMTD}

$6,8371-8411,2013$

Assessment of cloud phase products from the A-TRain

S. Zeng et al.

\section{Title Page}

Abstract Introduction

Conclusions

Tables

References

Figures

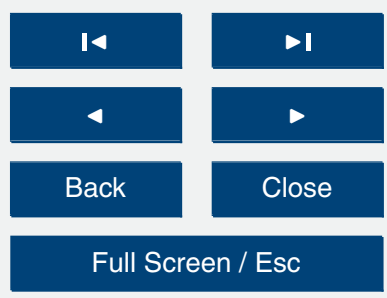

Printer-friendly Version

Interactive Discussion 
The latter with its warmer brightness temperature and a negative brightness temperature difference acts radiatively similarly to liquid clouds when using MODIS thermal infrared detection method.

\subsection{Bright or cold surfaces}

5 The bright or cold surfaces will induce a different surface brightness temperature. And also, over these regions, the atmosphere profiles can be quite different. These can produce issues when using IR bands in the MODIS phase detection algorithm. This can be noticed in Fig. 2 where the MODIS mixed phase clouds detected in disagreement with POLDER phase locate frequently over poles and the brighter and colder surface.

10 The abnormal atmosphere profiles (e.g. the inversion of temperature) over these regions are most likely to cause issues in phase detection as explained earlier when the physical basis of each retrieval method has been discussed.

\section{Conclusions}

Cloud phase is a critically important cloud parameter for cloud observation and modeling. Whether the clouds are ice or liquid is associated to the cloud formation and development processes and any changes in cloud phase could greatly impact the cloud radiative properties and feedback to the climate system. In this paper, we have concentrated on the statistical study of this key parameter from collocated observations of three sensors of the A-Train constellation. In view of the advantages and limitations of different phase retrieval methods used by POLDER, MODIS and CALIOP, we compared the phase products between the passive sensors, interpreted and validated the combination of phases derived from passive sensors against the one derived from the active sensor CALIOP. The validation and combination of these 3 different cloud phase products allow to provide more confident cloud phase information and gain more insight in case of ambiguous situations.
AMTD

6, 8371-8411, 2013

Assessment of cloud phase products from the A-TRain

S. Zeng et al.

\section{Title Page}

Abstract

Introduction

Conclusions

Tables

References

Figures

14

$\Delta$

4

Back

Close

\section{Full Screen / Esc}

Printer-friendly Version

Interactive Discussion 
This study dedicated to comparison and validation of different cloud phase products provides a global survey of cloud phase, allowing to establish distributions of the consistent (highly confident) and ambiguous cloud phase situations determined from POLDER and MODIS. A statistical analysis had been performed which provides a first 5 quantitative understanding of cloud phase distribution at global scale, together with an evaluation of the main uncertainties associated with the products. The angular biases in cloud phase detection existing in MODIS and POLDER products were also investigated.

The comparison of POLDER and MODIS phase products against CALIOP demon10 strated the high confidence that can be achieved in phase detection when both passive sensors agree. In addition, inconsistent phase decision between the two techniques can inform and be related to the presence of broken clouds, thin cirrus, heavy aerosols, snow, desert, supercooled water or multilayered clouds. From this study we have seen that POLDER can erroneously detect broken clouds scenes and aerosols overlaying water clouds as mixed or ice phase. However it can correctly identify cloud phase in case of single layered thin cirrus, water clouds over snow and the supercooled water clouds. Compared to POLDER, MODIS detects better the thin cirrus above water clouds and demonstrates better skills in identifying correctly the phase of broken clouds.

CALIOP agrees for more than $95 \%$ of the confident phase cases while for inconsistent and less confident phases, CALIOP partially agrees with either POLDER or MODIS, but preferentially with POLDER certainly because of both instruments extract phase information from polarization characteristics of clouds.

This analysis and the joint POLDER/MODIS dataset that has been created open 25 numerous perspectives for a better description of cloud thermodynamic phase at global scale. As a synergistic phase algorithm has been created from the PM Dataset (Riedi et al., 2010), more investigations are needed for this new phase product, which will help to quantify the value of the combined POLDER/MODIS retrieval techniques. This high confidence dataset could also be used to assess other cloud phase products de-

\section{AMTD}

6, 8371-8411, 2013

Assessment of cloud phase products from the A-TRain

S. Zeng et al.

\section{Title Page}

Abstract Introduction

Conclusions

Tables

References

Figures

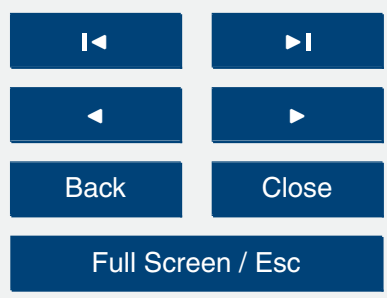

Printer-friendly Version

Interactive Discussion 
rived from different instruments than those used in this study. The joint products used in our analysis also provide an invaluable source of information for studying cloud processes such as phase transition or the impact of aerosols on nucleation and glaciation mechanisms.

5 Finally, it is anticipated that the combination of POLDER and MODIS illustrated here will prefigure what can be achieved from the combination of the 3MI and METIMAGE sensors on EPS-SG (EUMETSAT Polar System - Second Generation). This will hopefully foster the use of such cloud products for the evaluation of parameterizations in weather forecast and climate models, and the development of assimilation tech10 niques for microphysical properties of clouds.

Acknowledgements. The authors are very grateful to CNES and NASA for providing the POLDER, MODIS, and CALIOP data used in this study. We thank the ICARE Data and Services Center for providing access to the data and for general assistance and development support. This research has been supported by CNES, CNRS, the University of Lille, and 15 Region Nord-Pas-de-Calais.

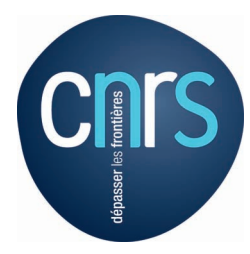

The publication of this article is financed by CNRS-INSU.

\section{References}

Baum, B. A., Soulen, P. F., Strabala, K. I., King, M. D., Ackerman, S. A., Menzel, W. P., and 20 Yang, P.: Remote sensing of cloud properties using MODIS airborne simulator imagery during SUCCESS: 2. Cloud thermodynamic phase, J. Geophys. Res., 105, 11781-11792, 2000. 8373, 8378

Bréon, F. M.: Reflectance of broken cloud fields: simulation and parameterization, J. Atmos. Sci., 49, 1221-1232, 1992. 8391
AMTD

$6,8371-8411,2013$

Assessment of cloud phase products from the A-TRain

S. Zeng et al.

Title Page

Abstract

Introduction

Conclusions

Tables

References

Figures

14

$\rightarrow 1$

4

Back

Close

Full Screen / Esc

Printer-friendly Version

Interactive Discussion $\triangleright$ 
Chepfer, H., Brogniez, G., Sauvage, L., Flamant, P. H., Trouillet, V., and Pelon, J.: Remote sensing of cirrus radiative parameters during EUCREX'94. Case study of 17 April 1994. Part II: Microphysical modelization, Mon. Weather Rev., 127, 504-518, 1999. 8380

Cho, H.-M., Nasiri, S. L., and Yang, P.: Application of CALIOP Measurements to the Evaluation 5 of Cloud Phase Derived from MODIS Infrared Channels, J. Appl. Meteor. Climatol., 48, 21692180, 2009. 8374

Chylek, P., Robinson, S., Dubey, M. K., King, M. D., Fu, Q., and Clodius, W. B.: Comparison of near-infrared and thermal infrared cloud phase detections, J. Geophys. Res., 111, D20203, doi:10.1029/2006JD007140, 2006. 8374, 8379, 8380

10 Curran, R. J. and Wu, M.-L. C.: Skylab Near Infrared Observations of Clouds Indicating. Supercooled Liquid Water Droplets, J. Atmos. Sci., 39, 635-647, 1982. 8377

Deschamps, P.-Y., Bréon, F.-M., Leroy, M., Podaire, A., Bricaud, A., Buriez, J.-C., and Sèze, G.: The POLDER mission: Instrument characteristics and scientific objectives, IEEE, 32, 598615, 1994. 8376

Fu, Q.: An accurate parameterization the solar radiative properties of cirrus clouds for climate models, J. Climate, 9, 2058-2082, 1996. 8373

Goloub, P., Deuzé, J.-L., Herman, M., and Fouquart, Y.: Analysis of the POLDER polarization measurements performed over cloud covers, IEEE Trans. Geosci. Remote Sens., 32, 78-88, 1994. 8376

20 Goloub, P., Chepfer, H., Herman, M., Brogniez, G., and Parol, F.: Use of polarization for cloud study, Proc. SPIE, 3121, 330-341, 1997. 8380

Goloub, P., Herman, M., Chepfer, H., Riedi, J., Brogniez, G., Couvert, P., and Séze, G.: Cloud Thermodynamical Phase Classification from the POLDER Spaceborne instrument, J. Geophy. Res., 105, 14747-14759, 2000. 8373, 8374, 8376, 8377, 8380, 8393

Hansen, J. E.: Multiple scattering of polarized light in planetary atmospheres. Part II. Sunlight reflected by terrestrial water clouds, J. Atmos. Sci., 28, 1400-1426, 1971. 8373

Hu, Y., Winker, D., Vaughan, M., Lin, B., Omar, A., Trepte, C., Flittner, D., Yang, P., Sun, W., Liu, Z., Wang, Z., Young, S., Stamnes, K., Huang, J., Kuehn, R., Baum, B., and Holz, R. : CALIPSO/CALIOP Cloud Phase Discrimination Algorithm, J. Atmos. Oceanic Technol., 26, $30 \quad$ 2293-2309, 2009. 8373, 8374, 8379, 8385, 8386, 8389

Kahn, B. H., Nasiri, S. L., Schreier, M. M., and Baum, B. A.: Impacts of subpixel cloud heterogeneity on infrared thermodynamic phase assessment, J. Geophy. Res., 116, doi:10.1029/2011JD015774, 2011. 8374, 8380
AMTD

$6,8371-8411,2013$

Assessment of cloud phase products from the A-TRain

S. Zeng et al.

\section{Title Page}

Abstract Introduction

Conclusions

Tables

References

Figures

14

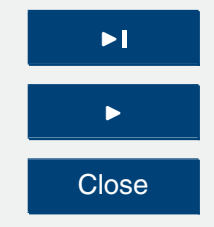

Back

Close

\section{Full Screen / Esc}

Printer-friendly Version

Interactive Discussion 
King, M. D., Tsay, S. C., Platnick, S. E., Wang, M., and Liou, K.-N.: Cloud Retrieval Algorithms for MODIS: Optical Thickness, Effective Particle, and Thermodynamic Phase, MODIS Algorithm Theoretical Basis Document, Version V ATBD-MOD-05, MODIS Science Team, 1997. 8377

5 King, M. D., Platnick, S., Yang, P., Arnold, G. T., Gray, M. A., Riedi, J. C., Ackerman, S. A., and Liou, K.-N.: Remote sensing of liquid water and ice cloud optical thickness, and effective radius in the arctic: Application of airborne multispectral MAS data, J. Atmos. Oceanic Technol., 21, 857-875, 2004. 8379

Lawson, R. P., Heymsfield, A. J., Aulenchach, S. M., and Jensen, T. L.: Shapes, sizes and light scattering properties of ice crystals cirrus and a persistent contrail during SUCESS, Geophys. Res. Lett., 25, 1331-1334, 1998. 8373

Menzel, W. P., Frey, R. A., Baum, B. A., and Zhang, H.: Cloud Top Properties and Cloud Phase., MODIS Algorithm Theoretical Basis Document ATBD-MOD-04, MODIS Science Team, 2006. 8378, 8380

Paltridge, G. W.: Infrared emissivity, short-wave albedo, and the microphysics of stratiform water clouds, J. Geophys. Res., 79, 4053-4058, 1974. 8373

Pilewskie, P. and Twomey, S.: Cloud phase discrimination by reflectance measurements near 1.6 and $2.2 \mu \mathrm{m}$, J. Atmos. Sci., 44, 3419-3420, 1987. 8373, 8377, 8379

Platnick, S., King, M. D., Ackerman, S. A., Menzel, W. P., Baum, B. A., Riedi, J., and Frey, R. A.: The MODIS Cloud Products: Algorithms and Examples from Terra, IEEE Trans. Geosci. Remote Sens., 41, 459-473, 2003. 8374, 8377

Pruppacher, H. R. and Klett, J. D.: Microphysics of Clouds and Precipitation, Kluwer Academic Pulishers, 1997. 8373

Riedi, J., Doutriaux-Boucher, M., Goloub, P., and Couvert, P.: Global distribution of cloud top phase from POLDER/ADEOS I, Geophys. Res. Lett., 27, 1707-1710, 2000. 8380

Riedi, J., Goloub, P., and Marchand, R. T.: Comparison of POLDER cloud phase retrievals to active remote sensors measurements at the ARM SGP site, Geophys. Res. Lett., 28, 21852188, 2001. 8380

Riedi, J., Marchant, B., Platnick, S., Baum, B. A., Thieuleux, F., Oudard, C., Parol, F., Nicolas, J.-M., and Dubuisson, P.: Cloud thermodynamic phase inferred from merged POLDER and MODIS data, Atmos. Chem. Phys., 10, 11851-11865, doi:10.5194/acp-10-11851-2010, 2010. $8374,8376,8379,8380,8381,8393,8397$

\section{AMTD}

$6,8371-8411,2013$

Assessment of cloud phase products from the A-TRain

S. Zeng et al.

\section{Title Page}

Abstract Introduction

Conclusions

Tables

References

Figures

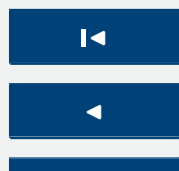

Back

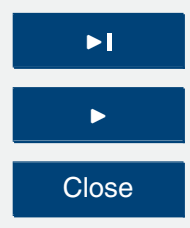

Full Screen / Esc

Printer-friendly Version

Interactive Discussion 
Spangenberg, D., Minnis, P., Shupe, M., Uttal, T., and Poellot, M.: Retrieval of Cloud Phase Using the Moderate Resolution. Imaging Spectroradiometer Data during the Mixed-Phase. Arctic Cloud Experiment., Fifteenth Atmospheric Radiation Measurement (ARM) Science Team Meeting, Daytona Beach, FL (US), 2005. 8374, 8380

5 Stephens, G. L., Paltridge, G. W., and Platt, C. M. R.: Radiation Profiles in Extended Water Clouds. III: Observations, J. Atmos. Sci., 35, 2133-2141, 1978. 8373

Strabala, K. I., Ackerman, S. A., and Menzel, W. P.: Cloud Properties inferred from 8-12- $\mu \mathrm{m}$ Data, J. Appl. Meteor., 33, 212-229, 1994. 8373

Vaughan, M. A., Young, S. A., Winker, D. M., Powell, K. A., Omar, A. H., Liu, Z., Hu, Y., and Hostetler, C. A.: Fully automated analysis of space-based lidar data: an overview of the CALIPSO retrieval algorithms and data products., Proc. SPIE, 5575, 16-30, 2004. 8379

Waquet, F., Riedi, J., C-Labonnote, L., Goloub, P., Cairns, B., Deuzé, J. L., and Tanré, D.: Aerosol remote sensing over clouds using the A-Train observations, J. Atmos. Sci., 66, 24682480, 2009. 8395

Wind, G., Platnick, S., King, M. D., Hubanks, P. A., Pavolonis, M. J., Heidinger, A. K., Yang, P., and Baum, B. A.: Multilayer Cloud Detection with the MODIS Near-Infrared Water Vapor Absorption Band, J. Appl. Meteorol. Climatol., 49, 2315-2333, 2010. 8382

Winker, D. M., Pelon, J., and McCormick, M. P.: The CALIPSO mission: spaceborne lidar for observation of aerosols and clouds, Proc. SPIE, 4893, 1-11, 2003. 8378

Wolters, E. L. A., Deneke, H. M., van den Hurk, B. J. J. M., Meirink, J. F., and Roebeling, R. A.: Broken and inhomogeneous cloud impact on satellite cloud particle effective radius and cloud-phase retrievals, J. Geophys. Res., 115, D10, doi:10.1029/2009JD012205, 2010. 8374

Young, S. A., Winkers, D. M., Vaughan, M. A., Hu, Y.-X., and Kuehn, R. E.: CALIOP ATBD, Part 4: Extinction Retrieval Algorithms., CALIOP ATBD No. PC-SCI-202 Part 3 Release 1.0-Draft, CALIPSO Science Team, 2008. 8392

Zeng, S., Parol, F., Riedi, Cornet, C., and Thieuleux, F.: Examination of POLDER/PARASOL and MODIS/Aqua Cloud Fractions and Properties Representativeness, J. Climate, 24, 44354450, 2011. 8375

\section{AMTD}

$6,8371-8411,2013$

Assessment of cloud phase products from the A-TRain

S. Zeng et al.

\section{Title Page}

Abstract

Introduction

Conclusions

Tables

References

Figures

14

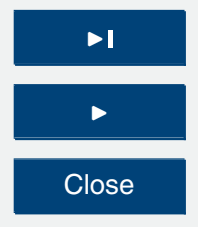

Back

Close

\section{Full Screen / Esc}

Printer-friendly Version

Interactive Discussion 


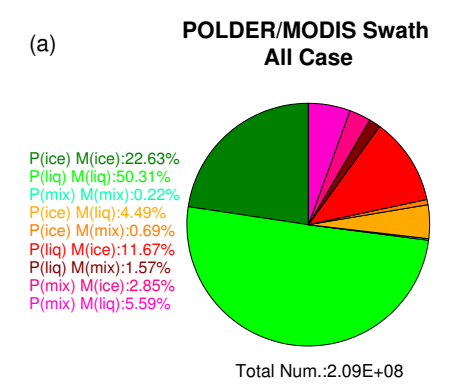

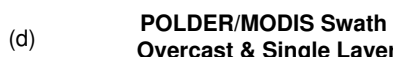

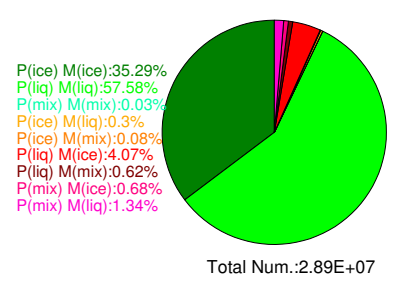

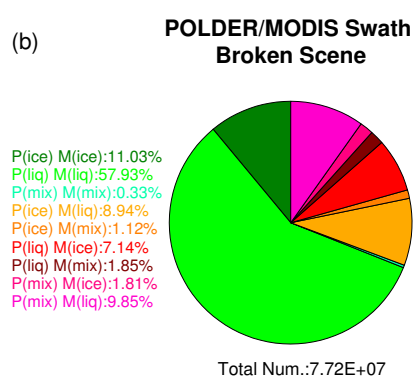

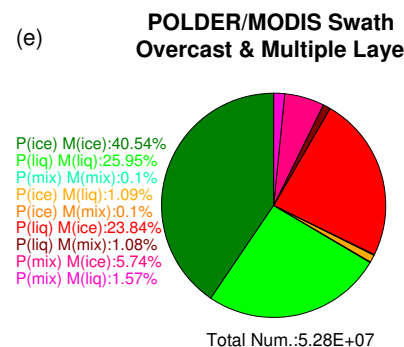

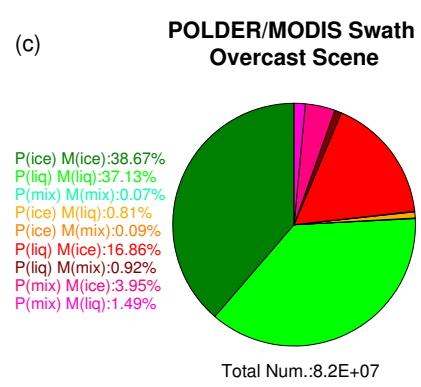

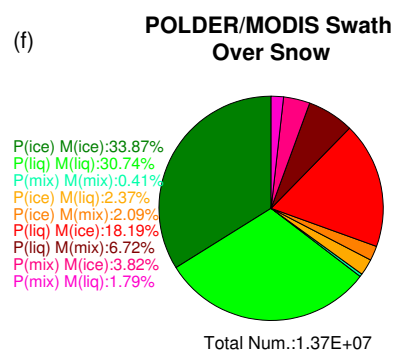

Fig. 1. Pie charts of the percentage of 9 combined phases (POLDER-ice \& MODIS-ice; POLDER-ice \& MODIS-liquid; POLDER-ice \& MODIS-mixed; POLDER-liquid \& MODIS-ice; POLDER-liquid \& MODIS-liquid; POLDER-liquid \& MODIS-mixed; POLDER-mixed \& MODISice; POLDER-mixed \& MODIS-liquid; POLDER-mixed \& MODIS-mixed) according to different cloudy conditions: all scenes (a), broken scenes (b), overcast scenes (c), overcast single layered scenes (d), overcast multilayered scenes (e) and scenes over snow/ice (f).

\section{AMTD}

\section{$6,8371-8411,2013$}

Assessment of cloud phase products from the A-TRain

\section{S. Zeng et al.}

\section{Title Page}

\section{Abstract}

Introduction

Conclusions

References

Tables

Figures

14

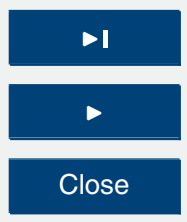

Back

Close

\section{Full Screen / Esc}

Printer-friendly Version

Interactive Discussion

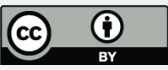



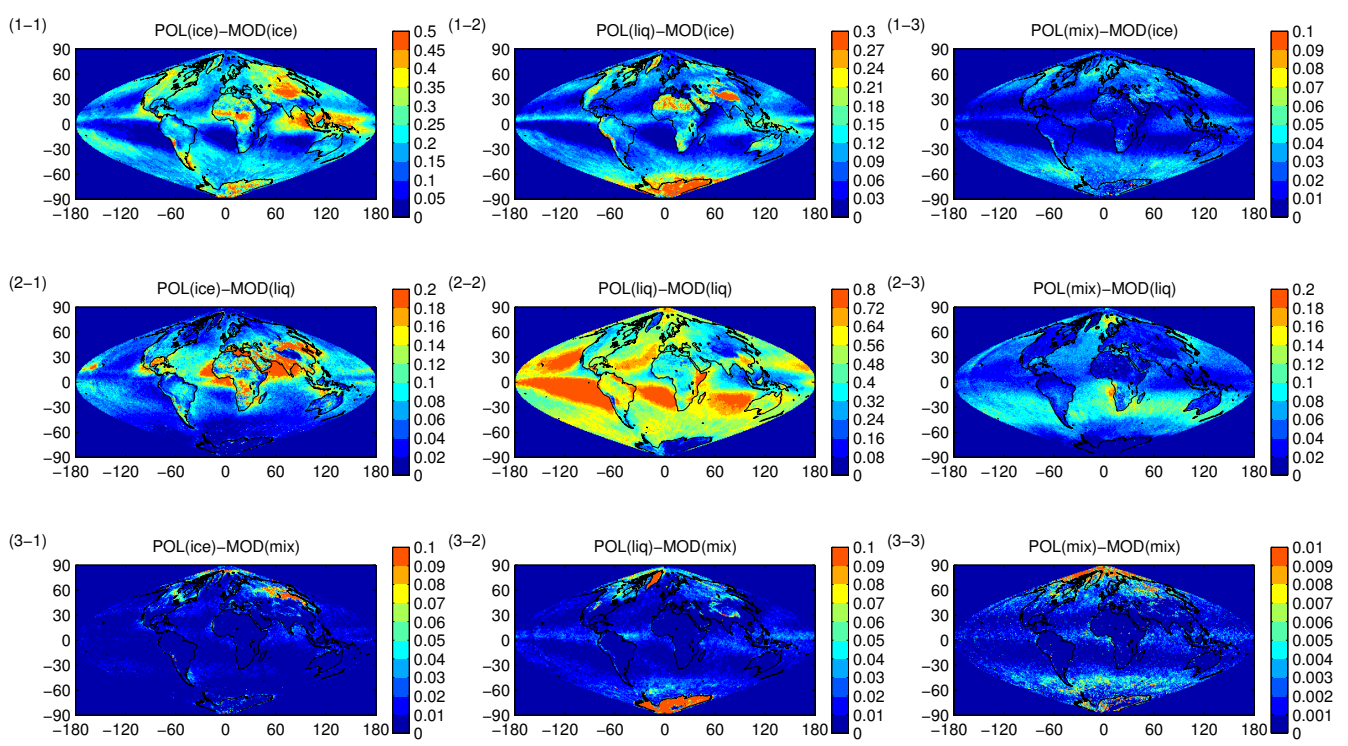

Fig. 2. Geographical distributions of the occurrence frequency of 9 combined phases: POLDER-ice \& MODIS-ice (1-1); POLDER-liquid \& MODIS-ice (1-2); POLDER-mixed \& MODIS-ice (1-3); POLDER-ice \& MODIS-liquid (2-1); POLDER-liquid \& MODIS-liquid (2-2); POLDER-mixed \& MODIS-liquid (2-3); POLDER-ice \& MODIS-mixed (3-1); POLDER-liquid \& MODIS-mixed (3-2); POLDER-mixed \& MODIS-mixed (3-3).

\section{AMTD}

\section{$6,8371-8411,2013$}

Assessment of cloud phase products from the A-TRain

\section{S. Zeng et al.}

\section{Title Page}

\section{Abstract}

Introduction

Conclusions

References

Tables

Figures

14

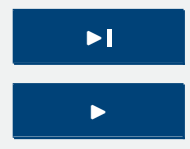

Back

Close

\section{Full Screen / Esc}

Printer-friendly Version

Interactive Discussion 
(1-1)POL(ice)-MOD(ice) total N. :1.2E+05

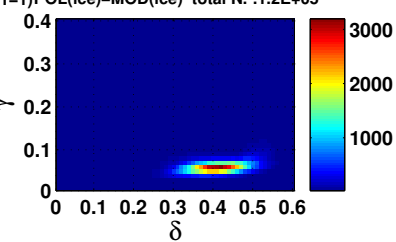

(2-1) POL(ice)-MOD(liq) total N. :7.4E+03

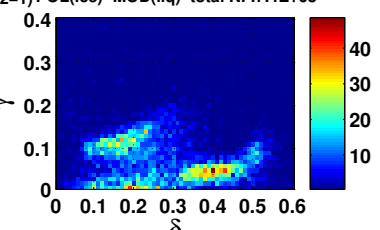

(3-1)POL(ice)-MOD(mix) total N. :1.1E+03

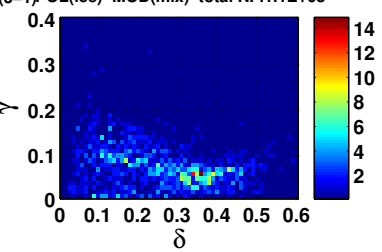

(1-2) POL(liq)-MOD(ice) total N. :1.9E+05

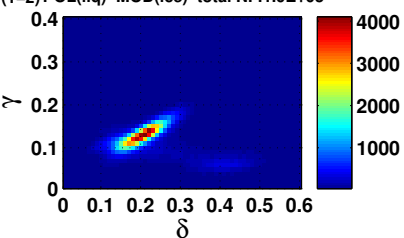

(2-2) POL(liq)-MOD(liq) total N. :9.1E+05

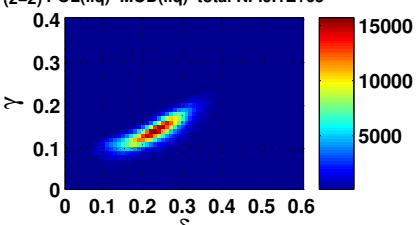

$\delta$

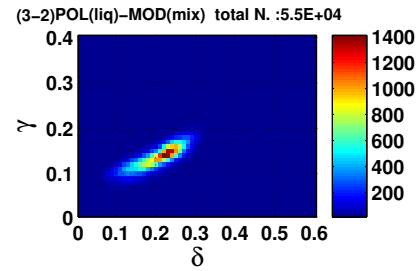

(1-3)POL(mix)-MOD(ice) total N. :2.3E+04

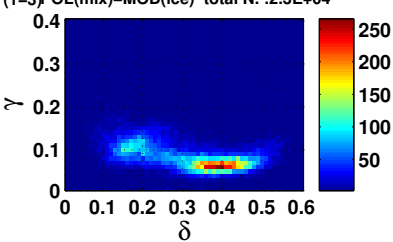

(2-3)POL(mix)-MOD(liq) total N. :3.5E+04

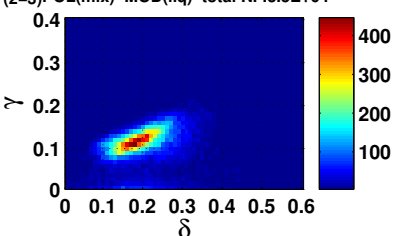

(3-3POL(mix)-MOD(mix) total N. : $1.9 \mathrm{E}+03$

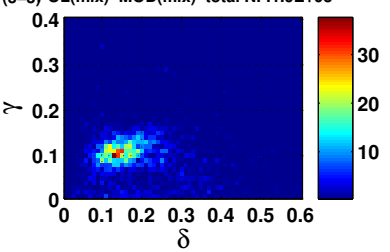

Fig. 3. One-year statistical features of the layer-integrated depolarization $(\delta)$ and the integrated attenuated backscatter at $532 \mathrm{~nm}(\gamma)$ for opaque clouds of 9 combined phases determined by POLDER and MODIS: POLDER-ice \& MODIS-ice (1-1); POLDER-liquid \& MODIS-ice (12); POLDER-mixed \& MODIS-ice (1-3); POLDER-ice \& MODIS-liquid (2-1); POLDER-liquid \& MODIS-liquid (2-2); POLDER-mixed \& MODIS-liquid (2-3); POLDER-ice \& MODIS-mixed (3-1); POLDER-liquid \& MODIS-mixed (3-2); POLDER-mixed \& MODIS-mixed (3-3).

\section{AMTD}

6, 8371-8411, 2013

Assessment of cloud phase products from the A-TRain

\section{S. Zeng et al.}

\section{Title Page}

Abstract

Introduction

Conclusions

References

Tables

Figures

14

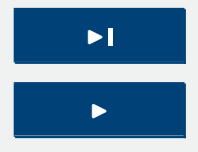

Back

Close

\section{Full Screen / Esc}

Printer-friendly Version

Interactive Discussion 

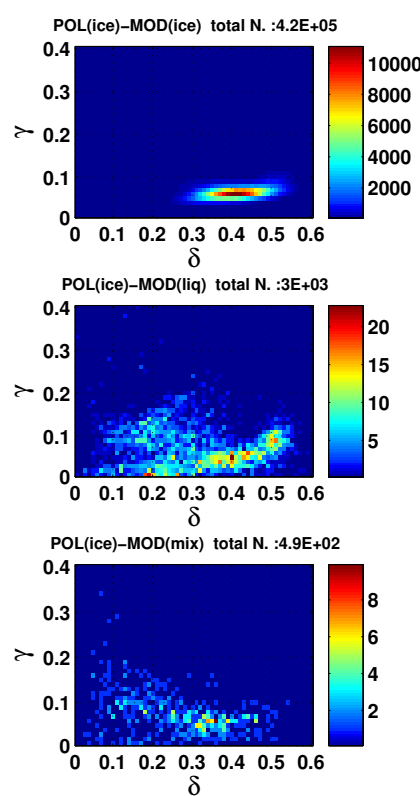
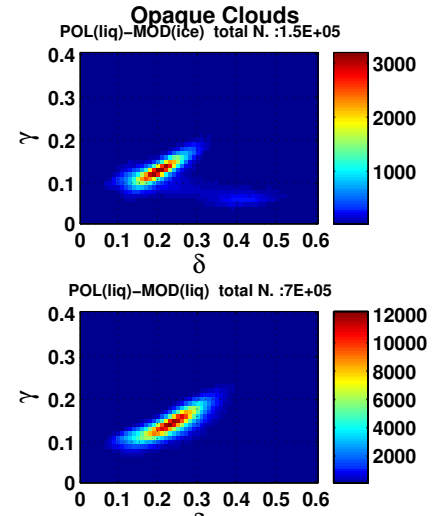

$\delta$

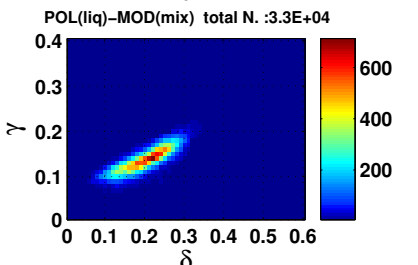

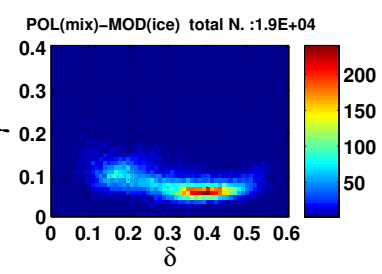

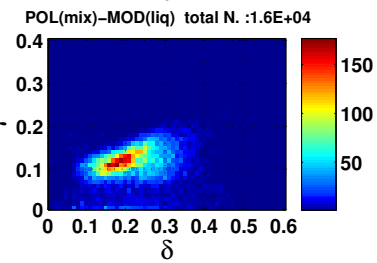

POL(mix)-MOD(mix) total N. :8.3E+02

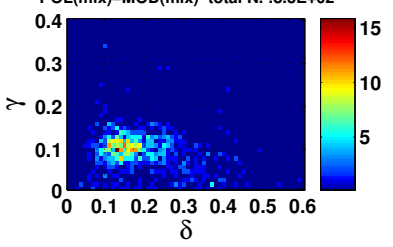

Fig. 4. One-year statistical features of the layer-integrated depolarization $(\delta)$ and the integrated attenuated backscatter at $532 \mathrm{~nm}(\gamma)$ for overcast opaque clouds of 9 combined phases determined by POLDER and MODIS: POLDER-ice \& MODIS-ice (1-1); POLDER-liquid \& MODIS-ice (1-2); POLDER-mixed \& MODIS-ice (1-3); POLDER-ice \& MODIS-liquid (2-1); POLDER-liquid \& MODIS-liquid (2-2); POLDER-mixed \& MODIS-liquid (2-3); POLDER-ice \& MODIS-mixed (3-1); POLDER-liquid \& MODIS-mixed (3-2); POLDER-mixed \& MODIS-mixed (3-3).

AMTD

$6,8371-8411,2013$

Assessment of cloud phase products from the A-TRain

S. Zeng et al.

\section{Title Page}

\section{Abstract}

Introduction

Conclusions

References

Tables

Figures

14

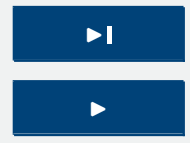

4

Back

Close

\section{Full Screen / Esc}

Printer-friendly Version

Interactive Discussion

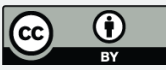




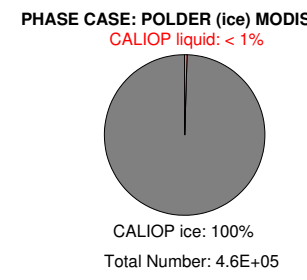

PHASE CASE: POLDER (ice) MODIS(liquid) CALIOP liquid: $36 \%$

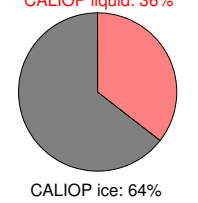

Total Number: 7.4E+03

PHASE CASE: POLDER (ice) MODIS(mixed)

CALIOP liquid: $30 \%$

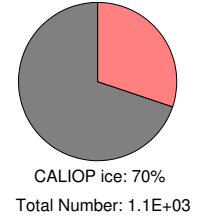

PHASE CASE: POLDER (liquid) MODIS(ice)

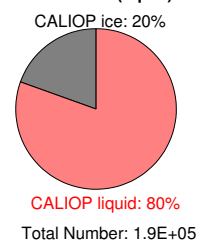

PHASE CASE: POLDER (liquid) MODIS(liquid) CALIOP ice: $5 \%$

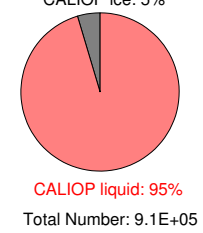

PHASE CASE: POLDER (liquid) MODIS(mixed)

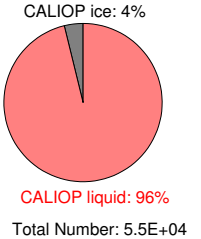

PHASE CASE: POLDER (mixed) MODIS(ice)

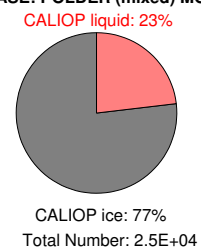

PHASE CASE: POLDER (mixed) MODIS(liquid) CALIOP ice: $21 \%$

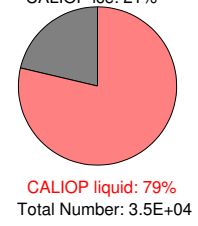

PHASE CASE: POLDER (mixed) MODIS(mixed)

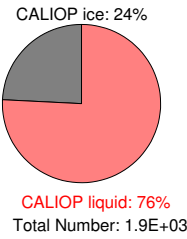

AMTD

6, 8371-8411, 2013

Assessment of cloud phase products from the A-TRain

S. Zeng et al.

\section{Title Page}

\section{Abstract}

Introduction

Conclusions

References

Tables

Figures

14

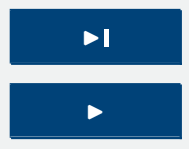

4

Back

Close

\section{Full Screen / Esc}

Printer-friendly Version

Interactive Discussion 
PHASE CASE: POLDER (ice) MODIS(ice)

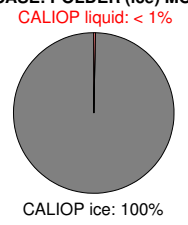

Total Number: $4.2 \mathrm{E}+05$

PHASE CASE: POLDER (ice) MODIS(liquid) CALIOP liquid: $24 \%$

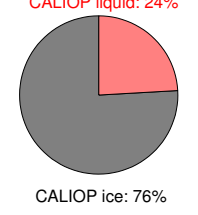

Total Number: $3 \mathrm{E}+03$

PHASE CASE: POLDER (ice) MODIS(mixed)

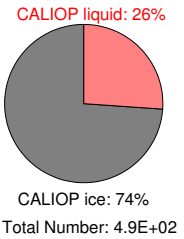

PHASE CASE: POLDER (liquid) MODIS(ice)

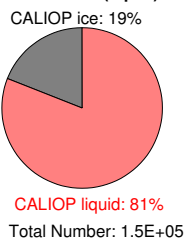

PHASE CASE: POLDER (liquid) MODIS(liquid)

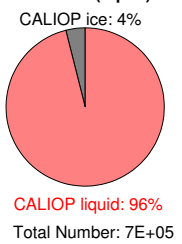

PHASE CASE: POLDER (liquid) MODIS(mixed) CALIOP ice: $3 \%$

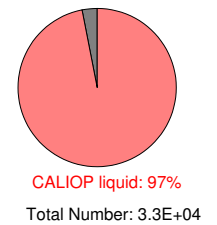

PHASE CASE: POLDER (mixed) MODIS(ice)

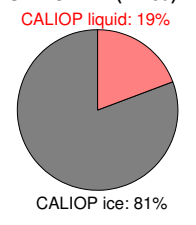

Total Number: $1.9 \mathrm{E}+04$

PHASE CASE: POLDER (mixed) MODIS(liquid) CALIOP ice: $27 \%$

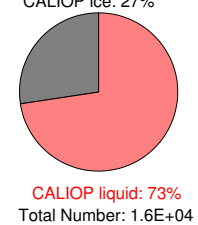

PHASE CASE: POLDER (mixed) MODIS(mixed) CALIOP ice: $29 \%$

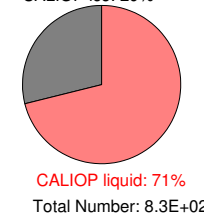

AMTD

6, 8371-8411, 2013

Assessment of cloud phase products from the A-TRain

S. Zeng et al.

\section{Title Page}

Abstract

Introduction

Conclusions

References

Tables

Figures

14

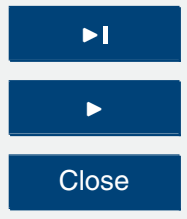

Back

Close

\section{Full Screen / Esc}

Printer-friendly Version

Interactive Discussion 
PHASE CASE: POLDER (ice) MODIS(ice)

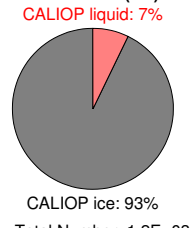

Total Number: $1.2 \mathrm{E}+03$

PHASE CASE: POLDER (ice) MODIS(liquid)

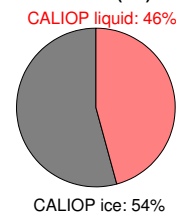

CALIOP ice: $54 \%$

Total Number: $1.1 \mathrm{E}+03$

PHASE CASE: POLDER (ice) MODIS(mixed)

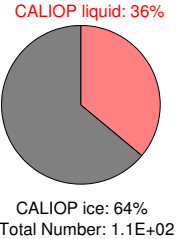

PHASE CASE: POLDER (liquid) MODIS(ice)

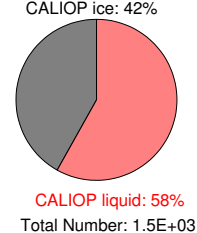

PHASE CASE: POLDER (liquid) MODIS(liquid) CALIOP ice: $21 \%$

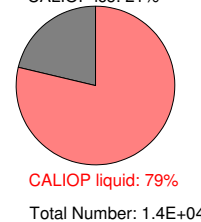

PHASE CASE: POLDER (liquid) MODIS(mixed)

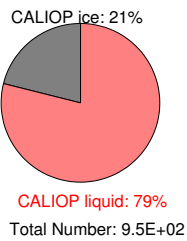

PHASE CASE: POLDER (mixed) MODIS(ice)

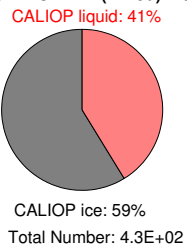

PHASE CASE: POLDER (mixed) MODIS(liquid) CALIOP ice: $24 \%$

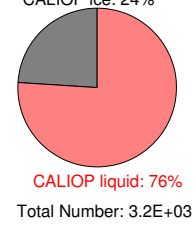

PHASE CASE: POLDER (mixed) MODIS(mixed)

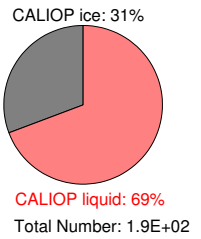

AMTD

6, 8371-8411, 2013

Assessment of cloud phase products from

the A-TRain

S. Zeng et al.

\section{Title Page}

Abstract

Introduction

Conclusions

References

Tables

Figures

14

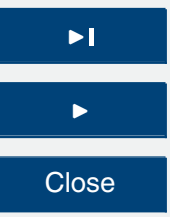

Back

Close

\section{Full Screen / Esc}

Printer-friendly Version

Interactive Discussion 

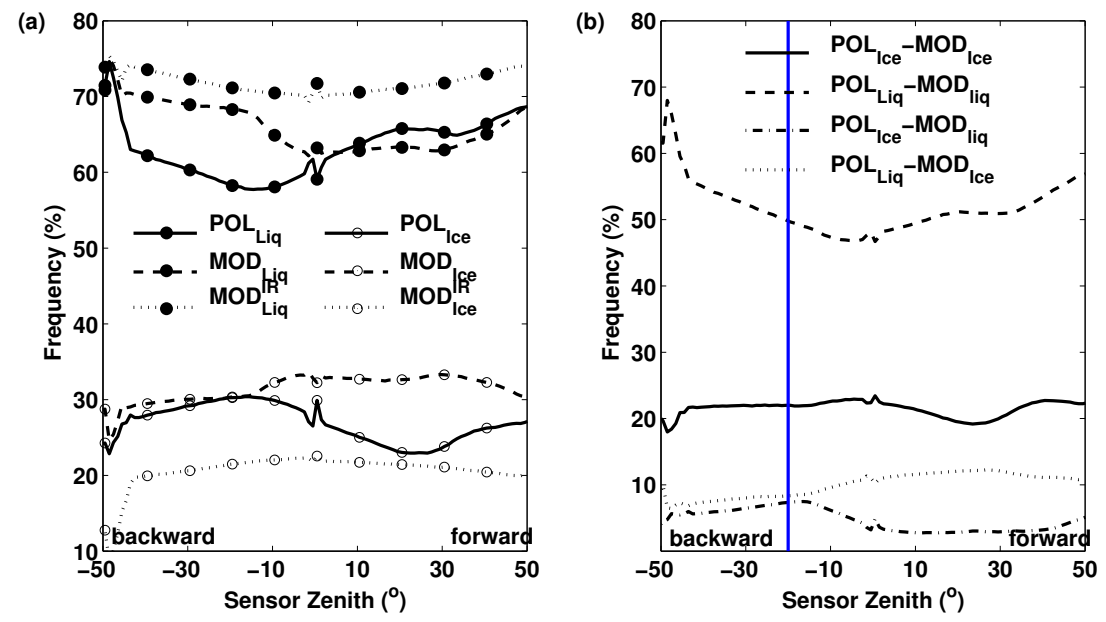

\section{AMTD}

6, 8371-8411, 2013

Assessment of cloud phase products from the A-TRain

\section{S. Zeng et al.}

\section{Title Page}

\section{Abstract}

Introduction

Conclusions

References

Tables

Figures

14

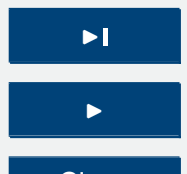

Back

Close

\section{Full Screen / Esc}

Printer-friendly Version

Interactive Discussion 

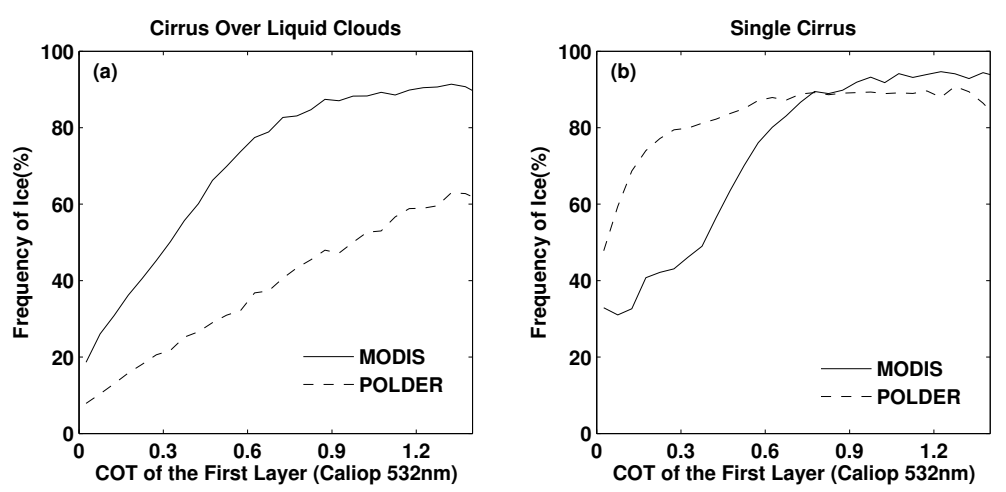

AMTD

\section{6, 8371-8411, 2013}

Assessment of cloud phase products from the A-TRain

\section{S. Zeng et al.}

\section{Title Page}
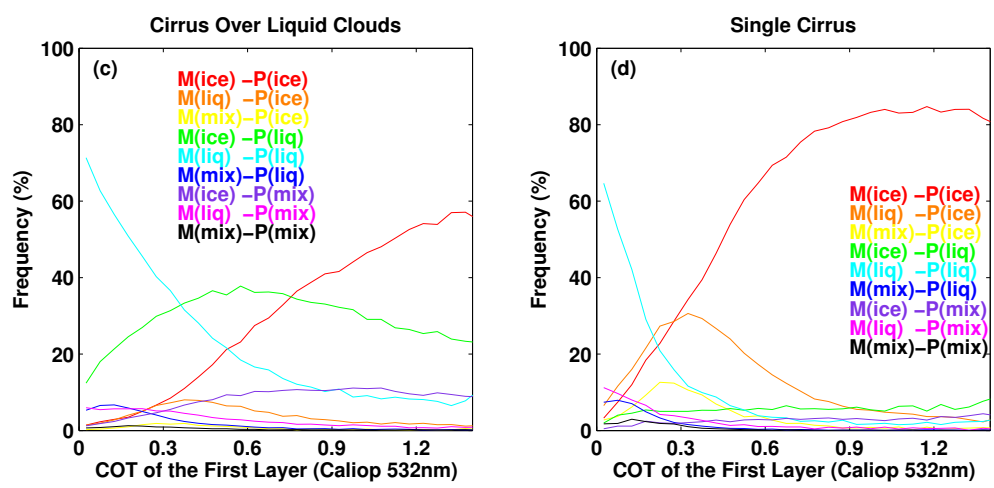

Abstract

Introduction

Conclusions

References

Tables

Figures
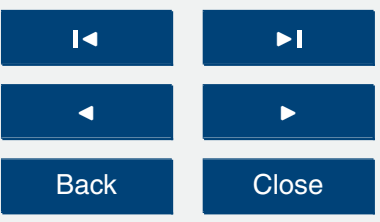

Back

Close

\section{Full Screen / Esc}

Fig. 9. The fraction of cloud phase classes derived from POLDER and MODIS against the optical thickness of the upper most cirrus determined by CALIOP: cirrus over water clouds (a), single layered cirrus (b) and the fraction of combined phases derived from POLDER and MODIS against the optical thickness of the upper most cirrus determined by CALIOP: cirrus over water clouds (c), single layered cirrus (d).

Interactive Discussion 


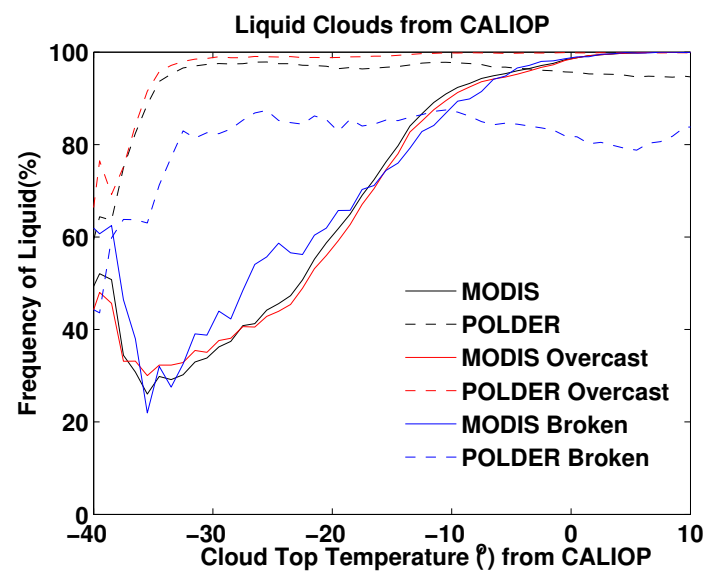

AMTD

$6,8371-8411,2013$

Assessment of cloud phase products from the A-TRain
S. Zeng et al.

Title Page

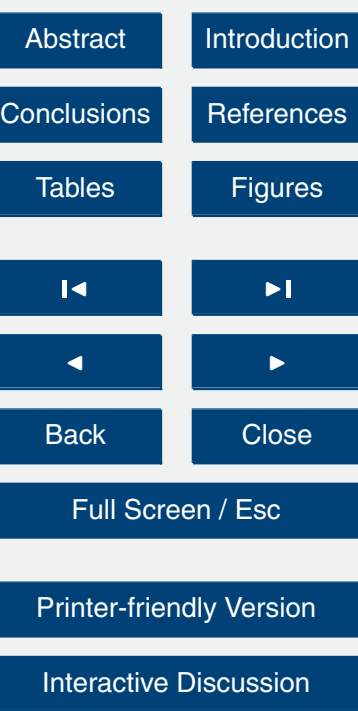

Fig. 10. The fraction of liquid clouds for POLDER and MODIS as a function of liquid cloud top temperature derived from CALIOP. 